\title{
Presence and Cybersickness in Virtual Reality Are Negatively Related: A Review
}

\author{
Séamas Weech ${ }^{1,2 *}$, Sophie Kenny ${ }^{2}$ and Michael Barnett-Cowan ${ }^{1,2}$ \\ ${ }^{1}$ Department of Kinesiology, University of Waterloo, Waterloo, ON, Canada, ${ }^{2}$ The Games Institute, University of Waterloo, \\ Waterloo, ON, Canada
}

In order to take advantage of the potential offered by the medium of virtual reality (VR), it will be essential to develop an understanding of how to maximize the desirable experience of "presence" in a virtual space ("being there"), and how to minimize the undesirable feeling of "cybersickness" (a constellation of discomfort symptoms experienced in VR). Although there have been frequent reports of a possible link between the observer's sense of presence and the experience of bodily discomfort

\section{OPEN ACCESS}

Edited by:

Maria V. Sanchez-Vives, August Pi i Sunyer Biomedical Research Institute (IDIBAPS), Spain

Reviewed by: Mariano Alcañiz, Universitat Politècnica de València Spain

Bruno Herbelin,

École Polytechnique Fédérale de Lausanne, Switzerland Massimo Bergamasco, Sant'Anna School of Advanced

Studies, Italy

*Correspondence:

Séamas Weech sweech@uwaterloo.ca

Specialty section: This article was submitted to Human-Media Interaction, a section of the journal Frontiers in Psychology

Received: 24 July 2018 Accepted: 16 January 2019 Published: 04 February 2019

Citation:

Weech S, Kenny S and Barnett-Cowan M (2019) Presence and Cybersickness in Virtual Reality Are Negatively Related: A Review.

Front. Psychol. 10:158. doi: 10.3389/fpsyg.2019.00158 in VR, the amount of literature that discusses the nature of the relationship is limited. Recent research has underlined the possibility that these variables have shared causes, and that both factors may be manipulated with a single approach. This review paper summarizes the concepts of presence and cybersickness and highlights the strengths and gaps in our understanding about their relationship. We review studies that have measured the association between presence and cybersickness, and conclude that the balance of evidence favors a negative relationship between the two factors which is driven principally by sensory integration processes. We also discuss how system immersiveness might play a role in modulating both presence and cybersickness. However, we identify a serious absence of high-powered studies that aim to reveal the nature of this relationship. Based on this evidence we propose recommendations for future studies investigating presence, cybersickness, and other related factors.

Keywords: presence, cybersickness, virtual reality, sensory integration, human factors

\section{INTRODUCTION}

Around 30 years ago, the process of simulating a user's sensory environment gained the popular term "virtual reality" (Krueger, 1992). Although the concept of virtual reality (VR) has morphed significantly since the initial conception, the promise inherent in simulating "the real world" has continually inspired and challenged scientists and artists (Jones, 2000). Fifty years ago, when the first attempts to implement a VR display were taking place, a large number of technical issues required a solution in order to achieve even a rudimentary mediated environment. While working at Harvard Computation Laboratory, Ivan Sutherland's team was able to solve many of these issues (Sutherland, 1968). Their stereoscopic display, including a refresh rate of 30 frames per second, a

\footnotetext{
${ }^{1}$ Although non-immersive desktop systems are sometimes referred to as "virtual reality," we use the term here to signify immersive or semi-immersive systems such as head-mounted displays or projection systems.
} 
field-of-view of $40^{\circ}$, and the ability to depict 3D objects only as wire-frames, was termed "favorable" by users. This implementation was some distance from providing the idealized VR experience. Since these initial inventions, a vast amount of effort has been focused on the development of improved means of inspecting and interacting with virtual worlds, and a myriad of other problems have since been solved. This rapid progress has led to the creation of VR systems that are orders of magnitude smaller, lighter, and more powerful than Sutherland's foundational technology. VR has recently seen popularity as a flexible tool for investigating a wide-range of human behaviors in high-fidelity with perfectly replicable conditions. Throughout the development process, however, the ultimate goal for VR has remained unachievable - that is, the accurate and credible simulation of a real experience. Chief among the enduring problems that prevent this achievement is the struggle to consistently generate a sense of presence in VR users, whereby conscious awareness of simulated mediation ceases. A second prominent barrier is cybersickness ${ }^{2}$ (CS), the bodily discomfort associated with exposure to VR content. Unlocking the potential of VR will largely depend on our ability to understand, then to solve, these substantial and enduring hindrances. A large body of research has emerged from attempts to identify whether presence and CS are deterministically linked through a positive or negative association. However, these results are highly discordant, and no consensus currently exists regarding the nature of the relationship between CS and presence.

This review has three aims. In the first part of this article we describe in brief the concepts of presence and CS and outline techniques that are commonly used to measure both factors (Section "Introduction"). We intend this to provide the reader with relevant context for interpreting studies that are discussed later in the review. The concepts of CS and presence are discussed below (see Sections "Presence," and "Cybersickness"), but in brief, these are complex phenomena with a multitude of individual differences (e.g., sex, gaming experience) and external factors (e.g., control of navigation, visual display parameters) thought to influence their occurrence. Each factor has been targeted using several measurement techniques, all of which vary with respect to how the measured variable is operationalized.

The second part of this review highlights studies that have directly measured the link between presence and CS, which we identified through a scoping literature search (Section "Evidence of a Presence-Cybersickness Relationship"). Given the large and historic importance of understanding and improving the issues of presence and CS, numerous studies have measured both factors and have even identified relationships between them. However, while approaches to solving the problems of presence and CS in VR have been tackled separately in large numbers of recent research papers and reviews, evidence of a possible link between them has seen very little discussion, particularly in recent years.

\footnotetext{
${ }^{2}$ Note that this review includes discussion of several related phenomena, such as CS, visually-induced motion sickness (VIMS), and simulator sickness (SS). Due to the important differences between these phenomena (which we briefly discuss below), the reader is advised to consider that evidence of a relationship between vection and VIMS, for example, does not dictate the same association between vection and CS
}

VR has developed rapidly since its first implementation in the 1960s, and as such, early reports on the link between presence and CS may not apply to the current state of VR.

The third part of the review constitutes a broad overview of the associations between presence, CS, and other variables, since a large number of contradictory findings have been reported in the literature. These confounding factors emerge in part due to the rapid rise of VR, the multifactorial nature of both CS and presence, and the influence of other modulating factors such as sensory mismatch, display factors, and personal characteristics (Section "Associations with Other Variables").

In our final section, and throughout the article, we aim to provide a synthesis of the research, with a special focus on unifying the discrepant findings about the nature of the presence-CS association. Our conclusions can be summarized as follows. First, there is more compelling evidence in support of a negative association between CS and presence than alternative relationships. The experimental results indicating a positive correlation between the two factors may be attributed to the necessity for settings to be "immersive" before CS can emerge. Second, there is considerable evidence for the role of sensory mismatch in both presence and CS. We also discuss the likelihood that sensory mismatch modulates a variety of factors that have been empirically linked with presence and CS (e.g., navigation control, display factors, vection). The strength of our conclusion is tempered by a need for additional high-powered studies in future research.

Our objective with this review is to provide an answer to the following question: What is the relationship between presence and CS in VR? Note that this review does not constitute a review of CS (see LaViola, 2000; Davis et al., 2014; Rebenitsch and Owen, 2016) or of presence (see Lombard and Ditton, 1997; Schuemie et al., 2001; Sadowski and Stanney, 2002; Biocca et al., 2003; Lee, 2004; Sanchez-Vives and Slater, 2005; for a metaanalysis see Cummings and Bailenson, 2016), but rather, of their interrelation. We address this relationship in order to answer pertinent questions in VR research: Does improving presence come at the cost of increasing CS, or can an intervention be conceived that improves presence and reduces CS? The second objective of this review is to provide a condensed view of the field of presence-CS research which we hope will prove useful to the next wave of studies on this complex relationship. While the majority of this review is focused on findings obtained in the disciplines of cognitive neuroscience and experimental psychology, the conclusions of the review are naturally relevant to human-computer interaction and human factors research.

\section{Presence}

For over 40 years, the goal of achieving presence has been regarded as a defining aspect of a successful VR experience (Minsky, 1980). Although multiple definitions and dimensions of presence have been proposed (Sadowski and Stanney, 2002), the concept is almost universally described as the observer's sense of psychologically leaving their real location and feeling as if transported to a virtual environment. Put simply, presence is the illusion of "being there" (Heeter, 1992). A variety of factors influence the likelihood that a user feels presence in a virtual 
environment (see Section "Associations With Other Variables"). For instance, the earliest VR implementations were built with an understanding that presence depends upon receiving correlated multisensory inputs that convey a simulated environment (the cybernetic approach to VR; Minsky, 1980; Herbelin et al., 2015). Many consider presence to be associated with the degree of environmental interaction (Slater and Usoh, 1993) as well as the fidelity and realism of information about the simulated landscape that is conveyed to the sensory modalities (Witmer and Singer, 1994). Individual differences in susceptibility to presence also play a large role (Witmer and Singer, 1998). Distinctions have been made between types of presence: Physical presence, the sense of physical relocation of the observer (IJsselsteijn et al., 2000); and social presence, the sense of being collocated with virtual agents (Heeter, 1992; Lombard and Ditton, 1997; Biocca et al., 2003). Several researchers have noted important distinctions between presence - the feeling of "being there" - and related concepts, such as engrossment and immersion. An individual may be highly attentive to a task in VR (engrossed) without feeling presence; similarly, the degree to which an individual is shut-off from the real world by a VR system (immersion) may not determine presence (Barfield et al., 1995; Slater et al., 1996; Nichols et al., 2000). Others have emphasized that presence is strongly modulated by perception of motor affordances of objects in VR (Dalgarno and Lee, 2010; Triberti and Riva, 2016), in addition to the importance of embodying a plausible virtual avatar in encouraging the sense that a virtual space is "real" rather than artifice (Slater et al., 2009; Grabarczyk and Pokropski, 2016). The embodiment of an avatar is in turn dependent on the synchronicity of sensory stimuli obtained by a VR user (Kilteni et al., 2012). At the same time, individual differences appear to modulate presence in response to VR content: Individuals who strongly express personality traits of openness, neuroticism, absorption, and extraversion tend to report higher levels of presence (Sacau et al., 2008; Weibel et al., 2010). The reason for this difference is unclear, although it is possible that the finding indicates a bias at the response level, rather than reflecting differences in the qualitative experience of presence across personality types.

\section{Measurements of Presence}

A wide range of methods have been used to measure presence in virtual environments. Although it has been argued that the subjective quality of presence necessitates a subjective measure such as verbal self-reports about the sense of "being there" (Sheridan, 1992), research has increasingly emphasized the need to measure the similarity between behavioral responses in the real world and in a mediated environment as an objective index of presence (Bailenson et al., 2004; Slater, 2004a; van Baren and IJsselsteijn, 2004). As such, presence measures are often classified as subjective or objective measures, which can be further broken down into subcategories.

Objective measures include biomarkers which might relate to presence (e.g., obtained from heart rate and skin conductivity), behavioral measures (e.g., reflexive responses to dangerous stimuli, postural sway in response to visual stimulation), or measurements related to task performance in the virtual environment. van Baren and IJsselsteijn (2004) provide a detailed list of examples that employ each category of measurement tool. However, several other techniques for measuring presence have been studied in recent years, including neuroimaging (functional magnetic resonance imaging, fMRI; Baumgartner et al., 2008; Clemente et al., 2013) and electroencephalogram (EEG; e.g., Baumgartner et al., 2006; Clemente et al., 2014) which show potential for identifying neural correlates of presence in VR. The search for objective markers of presence is particularly pressing, given that established presence questionnaires have been criticized for several limitations, including a lack of including an inability to quantitatively discriminate between otherwise clearly distinguishable virtual and real life experiences (Usoh et al., 2000), measuring the post-exposure memory of presence rather than presence itself (Usoh et al., 1999), and a lack of sensitivity to presence compared with behavioral measures (Bailenson et al., 2004; Slater, 2004a).

Subjective measures are obtained either through questionnaires administered following VR exposure; self-report ratings solicited during VR exposure; verbal or written reports of the qualitative experience of presence; or psychophysical magnitude estimation/matching paradigms. Despite their criticisms, questionnaires have been the most common approach to measuring presence. The dominant multi-item scales include the "Presence Questionnaire" (PQ; Witmer and Singer, 1998), a 32 -item list of seven-point questions that are used to generate scores on subscales such as realism, possibility to act, and quality of interface. The same authors developed the Immersive Tendencies Questionnaire (ITQ; Witmer and Singer, 1998) as an index of an individual's likelihood of feeling immersed in virtual settings. The 29 items of the ITQ relate to the tendency to become involved in activities, to maintain focus in activities, and the tendency to play video games. As such, the ITQ can be taken as an index of "trait" tendency toward feeling (or reporting) presence. Other common scales include the Igroup Presence Questionnaire (IPQ; Schubert, 2003), which was developed to measure spatial presence, involvement, and realness of a simulated experience, and comprises a list of 14 items. A popular scale developed by Slater, Usoh, and Steed (SUS; Usoh et al., 2000) consists of a brief, 6-item questionnaire that generates a single score to convey how "present" the user felt in the virtual setting. Many other scales have been employed, including Likert-type rating scales, analog (continuous) ratings, or single-item measures (e.g., "To what extent did you feel present in the environment, as if you were really there?" Bouchard et al., 2004).

Each variety of measurement scale is accompanied by benefits and shortcomings. While multi-item presence questionnaires can provide a detailed assessment of the multiple dimensions that may underlie presence, the appeal of single-item scales is in their un-intrusive and rapid assessment of presence (Bouchard et al., 2004). Single-item scales may also be less prone to memory deterioration following virtual environment exposure, and can be administered several times during exposure to VR (although it should be noted that repeat probing of a VR user may interrupt and diminish the experience of presence). When compared with lengthy questionnaires, single item scales are potentially more accessible to some participants, including children or individuals 
with learning difficulties. A thorough discussion of the limitations and utility of each type of scale is provided by van Baren and IJsselsteijn (2004).

\section{Cybersickness}

As with presence, several definitions have been proposed for what we term here CS. We follow the definition outlined by Stanney et al. (1997): CS is a constellation of symptoms of discomfort and malaise produced by VR exposure. CS is typically categorized as a form of visually induced motion sickness (VIMS), which describes any sickness produced by observation of visual motion, and it is distinct - but symptomatically similar to - simulator sickness (SS), which is produced by vehicle simulators. A slight distinction has been made between the experience of CS and SS; while CS is characterized by a prevalence of disorientation symptoms, SS appears to be predominated by oculomotor symptoms (Stanney et al., 1997). While many individuals experience CS in VR, others appear to be robust to the symptoms. Causal factors have been identified and discussed in great detail, including mismatches between observed and expected sensory signals (Reason and Brand, 1975; Rebenitsch and Owen, 2016), self-motion (McCauley and Sharkey, 1992), visual display characteristics (Moss and Muth, 2011), and gameplay experience (Knight and Arns, 2006; Gamito et al., 2008).

\section{Measurements of Cybersickness}

As with presence, the magnitude of CS experienced by a VR user has been estimated using both objective and subjective measures. Objective measures may involve analysis of physiological markers. Increases in bradygastric activity, respiration rate (Kim et al., 2005; Dennison et al., 2016) heart rate (Nalivaiko et al., 2015), and skin conductance at the forehead (Golding, 1992; Gavgani et al., 2017) provide robust measures of CS. Behavioral signs such as early termination of a VR experience (Kinsella, 2014) and task competence (Lin et al., 2015; Nalivaiko et al., 2015) also indicate the extent to which an individual experiences CS.

The most common approach to assessing CS involves subjective measures, particularly multi-item questionnaires such as the Simulator Sickness Questionnaire (SSQ; Kennedy et al., 1993) which includes 16 items (e.g., eyestrain, dizziness, and headache) on a four-point scale (none, slight, moderate, or severe). Common practice with the SSQ is to generate a total sickness score as well as scores for each subscale of oculomotor discomfort, disorientation, and nausea. A shortened version of the SSQ (Short Symptoms Checklist, SSC; Cobb et al., 1995), consisting of two items from each subscale, has been developed and employed in a small number of studies (Wilson et al., 1997; Cobb et al., 1999). Given the dynamic nature of CS, which tends to increase during VR exposure and slowly dissipate following VR termination, there are clear challenges involved in using oneshot questionnaire measurements of CS. Single item scales for measuring CS have also been developed and validated, providing an efficient method for assessing the temporal evolution of CS (e.g., Fast Motion Sickness Scale; Keshavarz and Hecht, 2011b). The near future of CS research will likely involve an integrated approach, where physiological assessments (see
Section "Physiological Measures") are combined with multi-item and single-item questionnaires that are completed both during and after VR exposure.

\section{Shared Measurements of Presence and Cybersickness}

Multiple measurement techniques are common to both presence and CS. These can be broadly categorized as physiological markers (e.g., recordings of neural or dermal activity), or taskperformance based measures (e.g., reaction times, performance accuracy). Here we describe these approaches to measuring both factors, and discuss how the overlap between measurement approaches causes difficulty with interpreting the true relatedness of the factors.

\section{Physiological Measures}

Physiological methods have been applied to the measurement of both presence and CS, which presents a significant potential problem in understanding how the two factors are related. Indices of autonomic nervous system activity offer reliable measures of the stress response, and this stress/alarm response is linked to both presence and CS. Physiological correlates of acute CS symptomatology (sweating, nausea, skin pallor, and increased heart rate) reflect the neuroendocrine stress response (Harm, 2002; Kim et al., 2005; Ohyama et al., 2007). Equally, the magnitude of a stress response to a virtual environment is often considered an indicator of presence (Bouchard et al., 2008; Ling et al., 2013). Research on presence in stressful environments (such as standing at the top of a height) suggests that assigning a personal relevance to the environment due to presence (e.g., "I could really fall into this pit") leads to heightened physiological reactions such as increased heart rate and skin conductance (Meehan et al., 2001, 2003; Wiederhold et al., 2001; Zimmons and Panter, 2003) This physiological response is thought to be caused by the release of adrenocorticotropin hormone (ACTH), growth hormone, and other hormones by the pituitary gland (Harm, 2002). We are unaware of any studies that assess hormonal correlates of presence, although the neuroendocrine response to motion sickness has been studied extensively. Evidence from physiology indicates that the secretion rate of ACTH and vasopressin in response to a visual motion stimulus is correlated with susceptibility to motion sickness (Eversmann et al., 1978; Kohl, 1985; Kim et al., 1997). In support of this physiological basis, Asian individuals are more susceptible to motion sickness, which may be related to the increased levels of vasopressin release observed in this population (Stern et al., 1996; Klosterhalfen et al., 2005). Neurophysiology studies have also produced an advanced understanding of the brain mechanisms underlying motion sickness. The emetic component of motion sickness is thought to be controlled by a pathway that involves the vestibular nuclei in the brainstem (Yates et al., 1998). These nuclei, which produce emesis when externally stimulated (Miller and Wilson, 1983), show modulated activity in response to levels of hormones and neurotransmitters such as GABA, dopamine, and ACTH (Balaban et al., 1989). A primary function of the vestibular nuclei is to project information about self-motion to the thalamus and vestibular cortex (Glover, 2009), and it has been 
claimed that incongruent sources of self-motion information that are integrated here significantly contribute to CS (Yates et al., 1998; Oman and Cullen, 2014; further discussion can be found at Section "Sensory Mismatch"). On the other hand, our understanding of the neural mechanisms for feeling presence are much weaker; understandably so, given the much more qualitative and phenomenological nature of presence. While there is some evidence from EEG and fMRI recordings that presence is associated with increased parietal and prefrontal cortex activation (Baumgartner et al., 2006, 2008), this field of research will likely grow rapidly given the recent increase in prevalence of VR technology.

\section{Task Performance}

Feeling present in a virtual space appears to enhance task performance. It has been shown that feeling presence is related to improved performance in the game of chess in VR (Slater et al., 1996), human interaction (Stanney et al., 2002), engine maintenance tasks (Cooper et al., 2016), and simple psychomotor tasks (Witmer and Singer, 1994; but c.f. Singer et al., 1995). In one study, a striking $95 \%$ of variability in presence ratings (PQ) was explained by variance in time to completion of an engineering task (Cooper et al., 2016). The conceptual link between presence and task performance appears weak, however (van Baren and IJsselsteijn, 2004), and it is possible that the relationship between presence and task performance measures is strongly mediated by other factors, such as experimental instructions, individual motivation, and even CS.

The inverse correlation between CS and task performance is well-supported, with several studies showing that symptoms of sickness are linked to decreased task performance (Frank et al., 1988; Kennedy and Fowlkes, 1992; Kennedy et al., 1993; Lerman et al., 1993; Nelson et al., 2000; Stanney et al., 2002; Kim et al., 2005). Ultimately, many who suffer from CS elect to terminate a session of VR early and therefore cannot complete the given task (DiZio and Lackner, 1997). In studies where no relationship between task performance and sickness severity is found, it is often claimed that symptoms were too mild to interfere with task performance (Nelson et al., 2000; Bos et al., 2005).

Using task performance to measure both CS and presence leads to some obvious problems in interpreting their relatedness. The evidence suggests that task performance is more indicative of CS than presence, although a conservative approach should be considered: Since task performance measures are likely to conflate multiple constructs, they are not ideal for use in isolation and should be used in conjunction with other metrics. Note that this caution applies equally to measures such as "enjoyment" as indices of presence or CS (e.g., Wilson et al., 1997; Slater, 2004b; Waterworth et al., 2015).

\section{EVIDENCE OF A PRESENCE-CYBERSICKNESS RELATIONSHIP}

There are a number of documented efforts to record presence and CS concurrently. Within this literature there is significant disagreement with respect to the strength and direction of the relationship. Here we outline a literature search of studies that report positive, negative, or null correlations between presence and CS, obtained using a structured literature search (Figure 1). We report the display device used, the task, the sample size, and statistics for each effect (if reported) in a summary table (Table 1) and an illustration (Figure 2). Finally, we identify where the more convincing evidence appears to lie, and discuss some possible reasons for the discordance in findings.

\section{Review Method and Results}

Our general method followed The PRISMA Statement (Moher et al., 2009), which provides a standardized set of items for reporting in systematic reviews. The primary aim of our review was to identify research studies that directly examine the relationship between presence and CS. Our criterion for inclusion was that the studies must have measured both presence and CS produced by the use of VR and analyzed the correlation between the factors. The method we used was to conduct a database search on PubMed, PsycINFO, and Google Scholar for publications that conducted experimental studies with VR (search term: virtual reality), including terms related to CS (cybersickness, nausea, sickness, or emetic), and terms related to presence (presence, immersion, immersiveness, or telepresence). Initially, there were 478 results returned. Figure 1 depicts the procedure for identifying and selecting records from the literature search.

As demonstrated by Figure 1, significant attrition occurred in the article selection process. We read the abstracts of all the papers and found that the vast majority of the results $(\sim 366$ of 404 records screened) referred to presence and CS briefly with regard to their relevance to the advancement of VR in rehabilitation, education, or consumer settings, or they used the search terms in a general sense. Several results containing instances of the key terms "presence" or "immersion" were unrelated to the sense of "being there" (e.g., "Cybersickness in the presence of scene rotational movements along different axes"; "immersion in VR" used as a synonym for "exposure to VR"; numerous other examples can be seen by the reader upon reproducing the search results). Terms such as "presence" are highly context-specific, and several studies not contained in the results use terms for CS that are general and difficult to identify with a literature review search, such as "negative effects." Another portion of the search results (18 records) measured only presence, or only CS, or measured neither. Many of these studies focused on the effect of an experimental manipulation on presence, where CS measures were collected solely in order to confirm that CS was low or negligible and was unaffected by the manipulation.

Table 1 provides an overview of each study identified using our search, including details of the VR task included in the experiment, the device used to depict the virtual environment, and the scales or measures used to acquire data on CS and presence. The table also includes the sample size and statistics for the relevant correlations. In numerous cases these details have not been reported by the study authors. Nonetheless, the details of the 20 publications that have directly measured the 


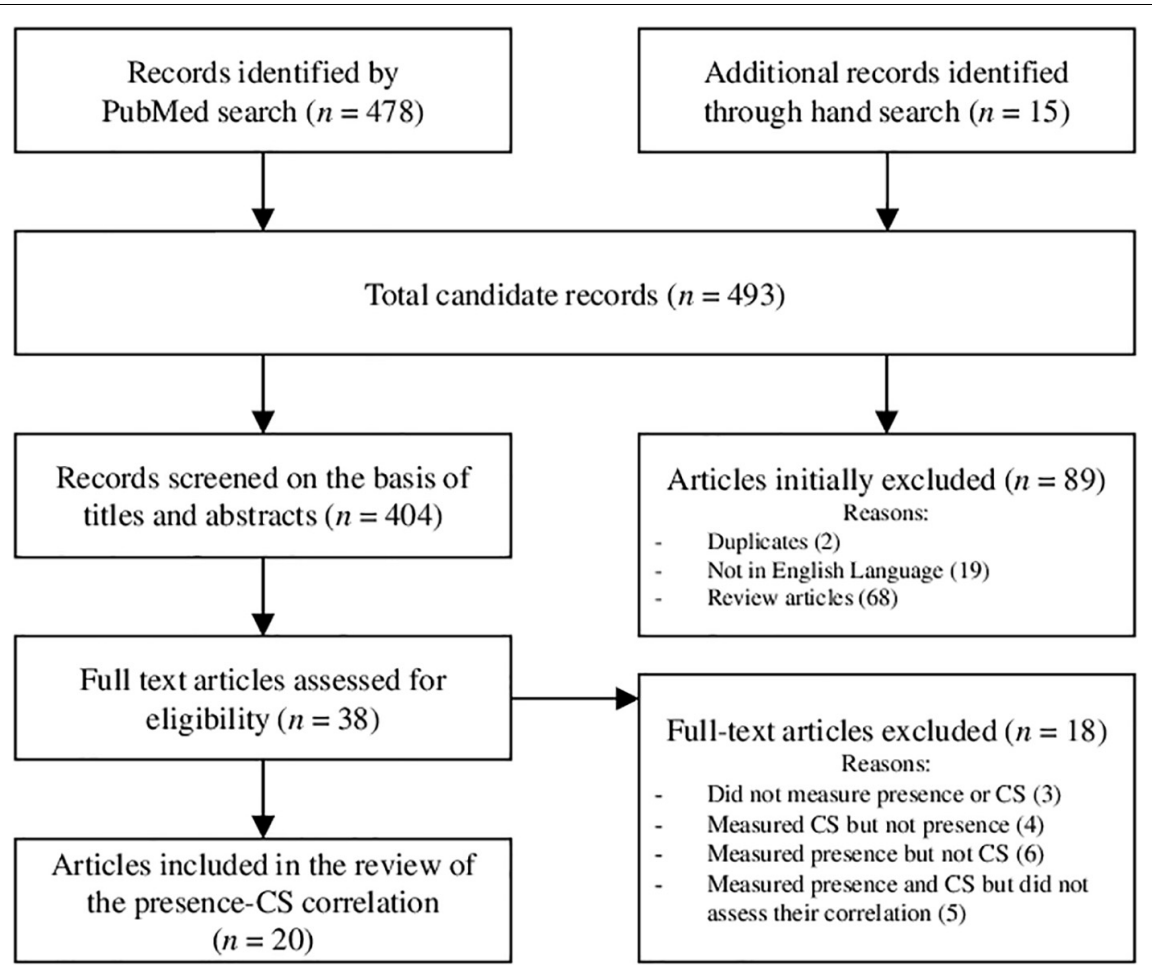

FIGURE 1 | PRISMA flowchart indicating the method for identifying and selecting articles that depict the relationship between presence and CS. Based on Moher et al. (2009).

correlation between presence and CS may prove informative for future studies on human factors in VR.

\section{Summary of Studies Identified by the Literature Search}

We describe the studies that we identified with the literature search below. We also describe the original authors' conclusion about the nature of the presence-CS association based on their findings, where this information was available. Following this summary, we outline our interpretation of how presence and CS are related based on a synthesis of the literature that we reviewed here (see Section "Conclusion: How Are Presence and Cybersickness Related?”).

\section{Studies Reporting a Negative Correlation}

Reports of negative correlations between presence and CS were reported early by Witmer et al. (1996) and Witmer and Singer (1998). Data from Witmer et al. (1996) showed a large negative correlation between scores on a presence questionnaire and self-reported symptom severity on a CS scale. The authors proposed that participants who experience symptoms are more internally focused and less able to process features of the environment, thus limiting the sense of presence.

Witmer and Singer (1998) reported data obtained in four experiments that helped to establish the Presence Questionnaire (PQ) and its relationship to CS. The significant reported correlation was taken as evidence that experiencing symptoms of
CS tends to diminish the feeling of presence via distraction or a reduction in the user's involvement in the virtual environment.

In a study carried out by Wilson et al. (1997), a negative relationship was observed between the interface quality subscale of the PQ and scores on the SSC scale in VR. The authors proposed that sickness symptoms may detract from presence, or that presence reduces the awareness of sickness symptoms. Evidence supporting this finding was gathered by Usoh et al. (1999) using a virtual room navigation task. Here, the oculomotor subscale of the CS scale used in this experiment was higher when presence scores were low, suggesting that oculomotor discomfort might have produced an internal focus in users.

Nichols et al. (2000) found evidence for a negative correlation between presence and CS during virtual house exploration. The task required several basic object manipulations (e.g., picking up and placing objects) using a three-dimensional mouse. A negative association between total CS ratings and presence scores was obtained following exposure to the virtual environment. The authors suggested that individuals with more symptoms of sickness may have concentrated less on the task, and may have been more attuned to the deficiencies of the virtual environment simulation (e.g., low refresh rate).

A negative relationship between subjective ratings of presence and sickness severity was obtained by Stanney (2000, Unpublished); reported informally by Stanney (2002). A negative correlation of a similar magnitude was obtained during virtual town navigation by Kim et al. (2005), who showed that CS and presence (particularly the feeling of "control" in the VR 
TABLE 1 | Studies assessing the presence-CS link: Negative, positive, and null correlations.

\begin{tabular}{|c|c|c|c|c|c|c|}
\hline Study & VR Task & Device & $N$ & Sign & Statistics & Measures \\
\hline Witmer et al., 1996 & Office navigation & $\begin{array}{l}\text { Fakespace Labs } \\
\text { BOOM2C }\end{array}$ & 22 & - & $r(20)=-0.60$ & $\begin{array}{l}\text { Presence: PQ } \\
\text { CS: SSQ }\end{array}$ \\
\hline Wilson et al., 1997 (1) & n.r. & Division dVisor & 20 & - & n.r. & $\begin{array}{l}\text { Presence: PQ } \\
\text { CS: SSC }\end{array}$ \\
\hline Witmer and Singer, 1998 & Multiple tasks & n.r. & n.r. & - & $r=-0.43$ across 4 exp. & $\begin{array}{l}\text { Presence: PQ } \\
\text { CS: SSQ }\end{array}$ \\
\hline Usoh et al., 1999 & Room navigation & Virtual Research V8 & 33 & - & n.r. & $\begin{array}{l}\text { Presence: SUS } \\
\text { CS: SSQ }\end{array}$ \\
\hline Nichols et al., 2000 & House navigation & Division dVisor & 20 & - & $r(18)=-0.58$ & $\begin{array}{l}\text { Presence: SUS } \\
\text { CS: SSQ }\end{array}$ \\
\hline Stanney, 2000, Unpublished & Maze navigation & n.r. & n.r. & - & $r=-0.34$ (d.f. n.r.) & n.r. \\
\hline Kim et al., 2005 (1) & Town navigation & Projection screen & 61 & - & $r(59)=-0.37$ & $\begin{array}{l}\text { Presence: PQ } \\
\text { CS: SSQ }\end{array}$ \\
\hline Knight and Arns, 2006 & n.r. & Projection screen & 387 & - & n.r. & $\begin{array}{l}\text { Presence: Likert } \\
\text { CS: SSQ }\end{array}$ \\
\hline Busscher et al., 2011 & Video observation & Cybermind Visette Pro & 43 & - & $r(41)=-0.33$ & $\begin{array}{l}\text { Presence: IPQ } \\
\text { CS: SSQ }\end{array}$ \\
\hline $\begin{array}{l}\text { Milleville-Pennel and Charron, } \\
2015\end{array}$ & Driving simulation & 3 LCD screen surround & 14 & - & n.r. & $\begin{array}{l}\text { Presence: Authors' } \\
\text { own scale } \\
\text { CS: SSQ }\end{array}$ \\
\hline Cooper et al., 2016 & Car wheel change & Projection screen & 8 & - & $r(6)=-0.63$ & $\begin{array}{l}\text { Presence: PQ } \\
\text { CS: SSQ }\end{array}$ \\
\hline Wilson et al., 1997 (2) & Duck shooting & Virtual I/O i-glasses & 24 & + & n.r. & $\begin{array}{l}\text { Presence: Startle, } \\
\text { subjective score } \\
\text { CS: SSC }\end{array}$ \\
\hline Bangay and Preston, 1998 & Rollercoaster & $\begin{array}{l}\text { HMD (model not } \\
\text { reported) }\end{array}$ & 143 & + & n.r. & $\begin{array}{l}\text { Presence: Subjective } \\
\text { score } \\
\text { CS: SSQ }\end{array}$ \\
\hline Lin et al., 2002 & Driving simulation & $\begin{array}{l}\text { Projection screen, } \\
\text { CrystalEyes glasses }\end{array}$ & 40 & + & $r(38)=0.44$ & $\begin{array}{l}\text { Presence: SUS } \\
\text { (modified) } \\
\text { CS: SSQ }\end{array}$ \\
\hline Kim et al., 2005 (2) & Town navigation & $\begin{array}{l}\text { 3D Visual and Auditory } \\
\text { Environment Generator }\end{array}$ & 61 & + & $r(59)=0.35$ & $\begin{array}{l}\text { Presence: ITQ } \\
\text { CS: SSQ }\end{array}$ \\
\hline Liu and Uang, 2011 & Grocery shopping & n.r. & 60 & + & $r(58)=0.67$ & $\begin{array}{l}\text { Presence: PQ } \\
\text { CS: SSQ }\end{array}$ \\
\hline Ling et al., 2013 & Public speaking & eMagin Z800 3DVisor & 88 & + & $r(86)=0.28(\mathrm{ITQ} / \mathrm{SSQ})$ & $\begin{array}{l}\text { Presence: ITQ } \\
\text { CS: SSQ }\end{array}$ \\
\hline Mania and Chalmers, 2001 & Listening to a seminar & Prototype HP HMD & 54 & $x$ & $r(16)=-0.4$ & $\begin{array}{l}\text { Presence: SUS } \\
\text { (modified) } \\
\text { CS: SSQ }\end{array}$ \\
\hline Seay et al., 2002 & Driving simulation & Projection screen & 156 & $\times$ & n.r. & $\begin{array}{l}\text { Presence: PQ } \\
\text { CS: SSQ }\end{array}$ \\
\hline Robillard et al., 2003 & $\begin{array}{l}\text { Asked to approach } \\
\text { phobogenic stimuli } \\
\text { (spiders) }\end{array}$ & I-Glass HMD & 26 & $\times$ & n.r. & $\begin{array}{l}\text { Presence: PQ, ITQ, } \\
\text { subjective score } \\
\text { CS: SSQ }\end{array}$ \\
\hline Ryan and Griffin, 2016 & Sitting in a café & Oculus Rift DK2 & 28 & $\times$ & n.r. & n.r. \\
\hline
\end{tabular}

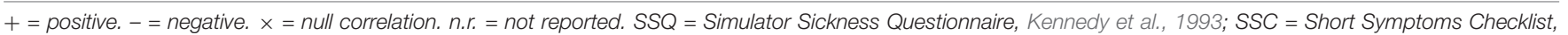

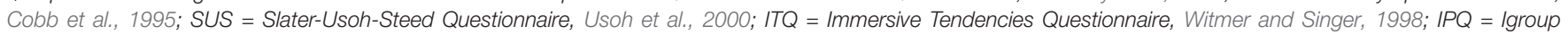
Presence Questionnaire, Schubert, 2003; PQ = Presence Questionnaire, Witmer and Singer, 1998.

environment) were negatively related. Unfortunately, while the same authors also obtained physiological signals (e.g., heart rate, EEG), they did not report the full set of possible correlations between physiological data, CS scores, and presence ratings.

A brief report of a large-sample study by Knight and Arns (2006) supported the existence of an inverse relation between presence and CS in immersive VR. The results showed significant chi-squared tests indicating that total SSQ scores decreased with increasing levels of presence. Knight and Arns (2006) also collected data on several other related factors, such as previous game play experience, motion sickness susceptibility, and participant sex, which permits inferences about latent causes for both presence and CS, although not all correlations between measures were reported (e.g., despite collecting gameplay experience, it was not specified if this factor was correlated with presence as in other studies; see Section "Gaming Experience"). 


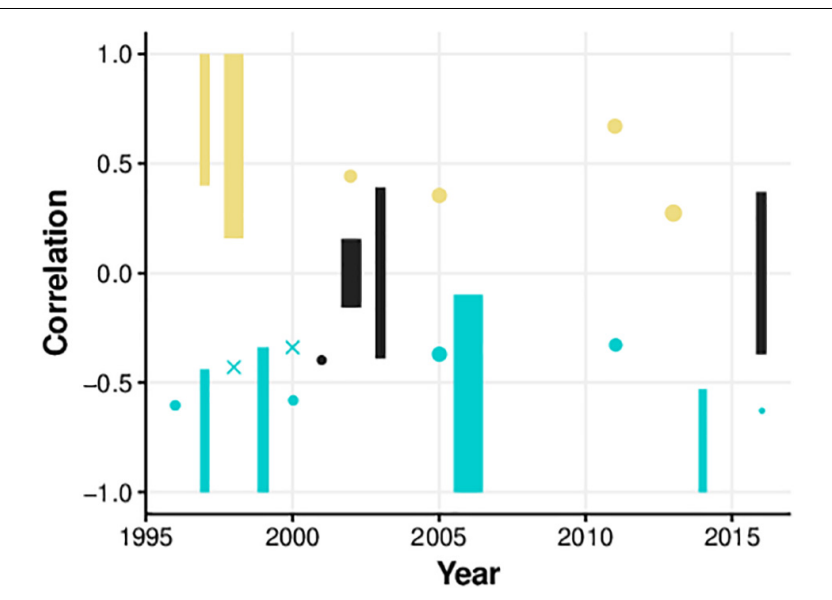

FIGURE 2 | Correlations by year of publication for experiments reported in Table 1. Width of elements reflects degrees of freedom (maximum $=385$, minimum $=6$ ). Yellow indicates positive correlations, cyan indicates negative correlations, and black indicates null correlations. Since some studies did not report correlation values, vertical bars are used to indicate the range of possible Pearson $r$ correlation values given the reported sample size. Crosses indicate that degrees of freedom were not reported.

Busscher et al. (2011) measured CS and presence while participants watched a video on a television in a simulated lounge environment. The authors described a significant negative correlation between the two factors and took this correlation as evidence that maximizing presence in VR leads to a suppression of CS, which was taken as evidence that future interventions may be able to tackle both issues concurrently.

A study using a partial least-squares regression method identified an inverse association between presence and CS in a driving simulation task (Milleville-Pennel and Charron, 2015). The authors collected several possible predictors of CS including driving experience, tendency toward frustration, and presence, and found that presence loaded negatively on a latent variable that was termed "pre-disposition to sickness." Milleville-Pennel and Charron also validated the single-factor construction of the SSQ and confirmed that the sub-components of the SSQ (nausea, oculomotor discomfort, and disorientation) each contribute approximately one third of the variance in overall levels of CS. This is an important finding given the high prevalence of SSQ use in studies of CS.

A recent study from Cooper et al. (2016) showed that subjective presence ratings were negatively associated with discomfort ratings that were collected following an immersive "pit stop" scenario. Although sample size was small $(N=8)$, the authors took the evidence as support for the utility of a multisensory cueing approach to improve presence and reduce the severity of sickness in VR.

\section{Studies Reporting a Positive Correlation}

As described above, Wilson et al. (1997) identified a negative correlation between presence and symptoms of sickness following the use of $\mathrm{VR}$ in one experiment, but in a second experiment, despite the fact that the same scales were used to measure the two factors, found evidence for the positive relationship. Participants conducted a virtual "duck shooting" task and completed a CS checklist, while behavioral (startle response) and subjective ratings of presence (presence questionnaires and awareness of background music manipulation) were collected.

Liu and Uang (2011) identified a positive relationship between presence and CS was in a virtual shopping task. Older adult participants were asked to search for specific items on shelves in a virtual grocery store. Results indicated a strong positive correlation between presence and CS, and the authors suggested an increase in presence causes CS to increase. An in-depth interpretation of the study is limited due to the fact that the authors did not specify certain details, such as the duration of VR exposure or the display device used.

Ling et al. (2013) report finding a positive link between CS and scores on the immersive tendency questionnaire (ITQ) that was administered after participants completed an anxiety-inducing task in VR. This was taken as evidence that individuals who experience more presence also experience more CS, and this conclusion was supported by evidence of a positive correlation between ITQ scores and levels of spatial presence. Despite these associations, there was no correlation found between spatial presence and CS. The authors suggested that the expected relationship between spatial presence and CS did not emerge due to the high cognitive demand of the public speaking task that may have modulated presence and CS in different ways.

Lin et al. (2002) obtained a strong positive correlation between presence and CS ratings in a CAVE-like driving simulator, from a sample of 10 participants. The authors state that there was a low level of interactivity in their VR task compared to other similar studies (e.g., Nichols et al., 2000, who found the opposite relationship), and noted that the level of interactivity afforded in virtual environments is likely to alter the relationship between presence and the severity of sickness.

As described above, Kim et al. (2005) identified a negative correlation between CS and presence ("user control" factor of the PQ). In the same study, the authors found that the direction of the relationship depended upon the questionnaire that was used: A positive correlation was documented between CS and the Involvement factor of the ITQ. This divergence was not discussed by the authors. This finding highlights one of the problems involved in characterizing presence, given the discrepancy between trait (ITQ involvement) and state (PQ control) measures of the phenomenon.

Slater et al. (1996) speculated that vection in VR was a common contributing factor to both CS and presence, stating that a positive correlation between presence and CS would therefore be "not surprising." Indeed, some of the more convincing (albeit, indirect) evidence of a positive CS-presence relationship has emerged from vection research. Hettinger et al. (1990) reported that a vection-inducing stimulus can produce VIMS, and more recently, Keshavarz et al. (2014) have shown that even "auditory vection" (i.e., vection produced by an auditory self-motion cue) can produce sickness symptoms. Other links between vection and VIMS have been discussed in a recent review (Keshavarz et al., 2015). Taken together with evidence of a strong relationship 
between vection and presence, it seems logical that increases in the sense of vection in a VE should improve presence, and also cause CS to increase. However, evidence on such a link is unclear (see Section "Vection").

\section{Studies Reporting a Null Correlation}

Some studies have reported null correlations between presence and CS. These reports are very sparse, possibly due to a bias for significant results (e.g., Open Science Collaboration, 2012, 2015). Mania and Chalmers (2001) report a study where participants were asked to observe a video in VR and to report their level of presence and CS. The authors found no significant relationship between presence and CS, perhaps because CS scores were quite low across participants, although a trend toward a negative correlation was observed.

In an investigation by Seay et al. (2002), a large sample of participants conducted a driving simulation task and reported their level of presence and CS. Results indicated no correlation between presence and any subscales of the CS measure. However, the same authors found main effects of an experimental manipulation - field-of-view angle, $180^{\circ}$ vs. $60^{\circ}-$ on both presence and the nausea subscale of their CS measure. In light of these inconsistent results, the authors concluded that factors such as field-of-view can prove to be a "double edged sword," increasing presence but also increasing sickness. Similarly, Bangay and Preston (1998) did not analyze whether a correlation existed between their measures of CS and presence, but identified that those who experienced CS were likely to report high levels of immersion in the VR environment.

A recent study found a null correlation between presence and CS while participants observed an animated avatar in a virtual café using a head-mounted display (Ryan and Griffin, 2016). It is unclear how CS was measured in this study, and levels of CS were also reported to have been very low which may have limited the power of the analysis. It is notable that of the studies reviewed here, this study is the only one to have used a modern consumeroriented VR device (Oculus Rift DK2). Since these devices have become extremely popular for VR research in recent times (Peer and Ponto, 2017), it is likely that studies on the presence-CS relationship in the coming years will use this device or a similar one, thus reducing much of the inter-experiment variability that is attributable to different display conditions.

\section{Conclusion: How Are Presence and Cybersickness Related?}

The balance of evidence favors the interpretation that presence and CS are negatively related. There are several reasons for this. First, the number of research studies that report the existence of a negative correlation outweighs the number of studies that report the opposite. Studies that describe an inverse relationship also tend to provide more compelling results: Where studies have observed a positive correlation between presence and CS, the study often fails to confirm this relationship in another section of the same study (e.g., Wilson et al., 1997; Kim et al., 2005; Ling et al., 2013). In some of the studies cited above that identified a positive correlation, interpretation of the data is limited by the absence of important details (e.g., Liu and Uang, 2011, did not describe device; Wilson et al., 1997, did not report test statistics).

Although a positive correlation between presence and CS has been anticipated or assumed by some researchers (e.g., McCauley and Sharkey, 1992; Slater et al., 1996), it is likely that positive associations arise due to the fact that "immersiveness" is required in order for an individual to experience CS. Immersiveness here refers to the extent of sensory "submersion" experienced by a user with a given VR system, such that external sensory cues are obstructed (Biocca and Delaney, 1995); accordingly, desktop systems and head-mounted displays (HMD) are classified as low and high in immersiveness, respectively. Observing a bright, dynamic movie on a desktop monitor is a comfortable experience for most, but viewing the same scene in a VR headset can often produce CS. Similarly, the sense of presence is heightened by the use of immersive systems. As such, immersion in VR leads to the possibility of both CS and presence emerging.

What mechanism causes this inverse association between CS and presence? It has been claimed that the sense of presence suppresses CS, since attention is directed away from intrusive factors such as sensory conflict (e.g., Busscher et al., 2011; Cooper et al., 2016). Alternatively, the distracting effects of CS may suppress attention to the VR environment that is required for presence to occur (e.g., Wilson et al., 1997; Witmer and Singer, 1998; Usoh et al., 1999; Nichols et al., 2000). More than likely, both of these assertions are true; they are not mutually exclusive. The relationship is also clearly mediated by other factors that appear to affect CS and presence inversely. A large number of associated variables have been identified, and although there is insufficient research to construct a precise model of their contribution to either factor, research suggests crucial roles played by sensory mismatch, display factors, navigation control, sex, and other factors (for an in-depth discussion, see Section "Associations With Other Variables").

There are also important limitations to several of the studies that reported negative presence-CS relationship, such as missing test statistics, or a failure to describe display device features. Many of the studies that reported a negative correlation were conducted before the advent of modern consumer-oriented VR technology, and their findings may not entirely replicate using current hardware devices. A major limitation of almost all studies described above is the small sample size used in the experiments. With one or two exceptions, the studies above on average wield very low statistical power for detecting medium effects. In the single case where an a priori power analysis was conducted, a desired power of $80 \%$, which is on the low-end of "adequate" (Button et al., 2013), requires approximately 85 participants. An a priori power analysis was reported in only one of the studies described here (Ling et al., 2013), and we estimate that only two other studies described here were likely to have attained $>80 \%$ statistical power: The brief report by Knight and Arns (2006), who measured a convenience sample of $N=387$; and a conference paper by Seay et al. (2002), who measured a sample of $N=156$. Evidently, there is a need for the adoption of a more scientifically rigorous approach toward statistical power, as has been reported widely across the fields of psychology and 
neuroscience (Open Science Collaboration, 2012, 2015; Button et al., 2013).

In Figure 2 we depict the correlation between CS and presence obtained in the studies that we reviewed and discussed here. On inspecting this figure, it is notable that very few recent studies have empirically examined the strength of the association between presence and CS. While recent literature often discusses both factors in the context of VR (e.g., Aardema et al., 2010; Terziman et al., 2010; Kober and Neuper, 2012; Serafin et al., 2016), they are often described only for the purpose of highlighting the nuisance of CS and the desirability of presence. For instance, presence and CS are both measured by Nolin et al. (2016), but the strength of correlation is not reported. Kober and Neuper (2012) stated that participants in their study of presence in VR also completed a CS questionnaire, but the authors only used these data to confirm that CS was at a low level overall. Similarly, Corrêa et al. (2017) assessed CS and presence, simply reporting that CS was low in the participants tested. Baus and Bouchard (2017) used high self-reported CS levels as an exclusion criterion, and did not assess the relationship with levels of presence. Kim $\mathrm{K}$. et al. (2012) also report a study where CS and presence measures were both collected, and although their manipulation (visual display device: Desktop/HMD/CAVE) affected both CS and presence, their relationship is not reported. While the nature of the presence-CS link may not have been a major focus of any of these studies, since the data clearly existed, it is rather unfortunate that no analysis was reported. The presentation of these data in future studies where the data are collected would provide valuable information to developers and researchers interested in advancing the understanding of the human experience in VR. It should also be noted that a diverse variety of VR technology has been used in the studies reported above, spanning from older display devices (e.g., Division dVisor, Fakespace BOOM2C) to more recent consumer headsets (Oculus Rift DK2). Modern VR devices such as HTC Vive and Oculus Rift CV1 are more similar to one another with respect to many characteristics (field-of-view, refresh rate, tracking latency) than were older systems (Peer and Ponto, 2017). Another limitation of the existing literature is a severe underreporting of the input techniques adopted for environmental navigation and interaction. In the coming years, the consistency of findings in the field of human factors in VR will likely benefit from a natural standardization of display tools.

\section{ASSOCIATIONS WITH OTHER VARIABLES}

As research has investigated the nature of the relationship between presence and CS, a variety of candidates for mediation of the relationship have emerged. Although no studies have attempted to estimate the magnitude of the contribution of each of these factors, here, we present a synthesis of the literature that offers clues as to the most important mediators on the presenceCS relationship. We make connections between these sometimes disparate studies, and highlight the interactions between some of the factors associated with both presence and CS.

\section{Sensory Mismatch}

Sensory cues gathered from multiple channels (proprioception, vision, vestibular, etc.) are used to perform continuous updating about the estimated state of the world and of the body (Calvert et al., 2004). Therefore, when simulating a virtual environment, congruence between the information that is obtained and that which is expected (either because of prior experience, or because of expected correlations with another sensory channel) plays a large role in the experience.

The understanding of how sensory mismatch contributes to CS and presence has historically been limited due to the challenge of directly manipulating or measuring sensory conflict in experimental settings (Riccio and Stoffregen, 1991; Oman and Cullen, 2014). For instance, only recently have convincing results emerged that are consistent with a neural signature for sensory mismatch (e.g., Brooks and Cullen, 2013, 2014). Nonetheless, theoretical accounts have highlighted the role played by the congruence of sensory cues in both presence (Slater et al., 1995; Bowman and McMahan, 2007; Henderson et al., 2007) and CS (Reason and Brand, 1975; Oman, 1991; Rebenitsch and Owen, 2016). It is clear that the addition of high-fidelity, multimodally congruent information is beneficial to an increase in presence. Participants in a VR navigation task show increased presence when binaural auditory information is presented compared to vision-alone conditions (Larsson et al., 2002). Introducing multisensory feedback cues (tactile, auditory, and visual) in a manual VR task also enhances presence (Cooper et al., 2016; also see Hecht et al., 2006). Viaud-Delmon et al. (2006) demonstrated that adding auditory cues to a virtual environment (i.e., enhancing the immersiveness of the simulation) increases presence, but also leads to a rise in levels of CS.

However, to our knowledge, there is little research on the disruption of presence when multimodal cues are in conflict. The most relevant literature in that context relates to vection, a strong correlate of presence (Riecke, 2010). The evidence of a relationship between vection and sensory mismatch is inconsistent: Visual-vestibular cue mismatch has been linked to a decreased sense of vection (Wong and Frost, 1981; Weech and Troje, 2017) or to enhanced vection (Kim J. et al., 2012; Palmisano et al., 2012; also see Section "Vection"). Future research will be needed to establish causality between cue conflict and presence, perhaps by assessing the tendency for breaks in presence when multimodal cues are put experimentally into conflict.

It has been theorized that CS in VR is produced as a result of mismatches in information across sensory streams, or conflicts between observed and expected sensory cues, particularly with respect to visual-vestibular cue conflict (Reason and Brand, 1975; Oman, 1991; Rebenitsch and Owen, 2016). The link between multimodal cue mismatch and the symptoms of CS has been attributed to the detection of sensory dysfunction (Treisman, 1977). Motivated by these theoretical accounts, several researchers have attempted to prevent CS through a sensory conflict reduction approach, with some successful results (e.g., Reed-Jones et al., 2007; Cevette et al., 2012; Gálvez-García 
et al., 2015; Zao et al., 2016). This research has produced evidence that CS symptoms are reduced when sensory stimulation is used to "recouple" multimodal streams of information in VR. Visualvestibular cue mismatch is a particular source of discomfort, and this manner of conflict is extremely common in VR applications (LaViola, 2000; Rebenitsch and Owen, 2016). By reducing this mismatch using vestibular stimulation, CS appears to be mitigated (Reed-Jones et al., 2007; Cevette et al., 2012; Gálvez-García et al., 2015). Other research has adopted a sensory reweighting approach to encourage conflicting cues to be quickly disregarded using "noisy" vestibular stimulation, rather than "recoupling" the sensory streams (Weech et al., 2018a). Taken together with work showing that vection is also facilitated when noise is applied to the vestibular sense (Weech and Troje, 2017), the sensory reweighting approach appears to be a promising method for maximizing presence and minimizing CS. However, further refinements of the sensory stimulation methods currently used will be vital before a viable practical application can be achieved.

\section{Display Factors}

Reports show that visual display characteristics such as frame rate and field-of-view influence both presence and CS. Higher frame rates are associated with higher self-reported presence ratings due to the increased realism afforded by smooth motion (Meehan et al., 2001). Low visual display frame rate ( $<20 \mathrm{fps})$ has long been known to generate motion sickness in simulated environments (e.g., Jones et al., 2004), leading to a focus on high, stable refresh rates in best practice guides for VR development (Oculus, 2017). This guide also emphasizes that latencies between observer motion and visual self-motion feedback should be minimized in order to avoid generating nausea, although the link between motion-to-photon latency and CS has been disputed (Meehan et al., 2003). Higher field-of-view also leads to increases in presence (Prothero and Hoffman, 1995), but at the same time, field-of-view increases lead to higher CS (Lin et al., 2002). It was suggested by Lin et al. (2002) that the effect of field-ofview on both factors might be mediated by its effect on illusory self-motion perception (vection) produced by large-field visual motion.

Evidence suggests that stereoscopy influences both presence and CS. Research has identified links between stereopsis and CS, likely due to the accommodation-vergence conflict introduced by stereoscopic 3D displays. For instance, viewing stimuli on certain 3D displays can increase measures of visual discomfort that are characteristic of CS, such as eyestrain (Emoto et al., 2004; Pölönen et al., 2009; Lambooij et al., 2011). As well, VIMS has a strong relationship to stereoscopy: Observing a simulated roller-coaster stereoscopically leads to increased VIMS symptoms compared to monocular viewing (Keshavarz and Hecht, 2012). Stereoscopic viewing of a virtual environment also takes advantage of the learned relationship between binocular disparity and object depth, increasing the naturalness of the viewing experience. Ling et al. (2013) show that providing stereoscopic cues appears to enhance presence (SUS; effect size Cohen's $d=0.24$ ) and spatial presence (IPQ; $d=0.29$ in a public speaking task. Although the authors also predicted a relationship between stereoscopic acuity and presence, no evidence of such a link was observed. The authors suggested the link between presence and stereoscopy may be even stronger than implied by their results, given that their public speaking task involved very little binocular disparity. Indeed, a stronger link was observed by IJsselsteijn et al. (2001) in a driving simulation task. Presence measured by subjective responses (continuous scale) showed a large increase due to stereoscopic presentation. The authors also found that a behavioral measure of presence, postural sway, also showed a tendency to increase when stereoscopic cues were added. Importantly, the authors also measured sickness in this study and identified no effect of stereoscopy on VIMS (continuous scale), although it should be noted that sickness ratings were near floor levels. These results were similar to those obtained by Ling et al. (2013), who found no difference in CS (SSQ) across stereoscopic and non-stereoscopic display conditions.

\section{Vection}

Vection is considered a strong correlate of presence. For an observer to experience the illusion of self-motion, their sensorimotor control system must be convinced that the visual motion veridically specifies their own body motion (Prothero and Hoffman, 1995; Chertoff and Schatz, 2014). However, if the implied body motion is not consistent with cues from other modalities (particularly vestibular signals), sensory conflicts emerge, producing nausea (Reason and Brand, 1975; Lin et al., 2002). Vection-inducing stimuli are often nauseogenic, but the relationship is complex. Some have suggested that experiencing vection might be a necessary prerequisite for experiencing VIMS (Hettinger et al., 1990; Hettinger and Riccio, 1992; Keshavarz et al., 2015). Motivated by this hypothesis, one study has characterized an optimal magnitude of visual motion that does not produce CS but still evokes vection (Tanaka and Takagi, 2004).

However, vection does not always lead to the emergence of sickness symptoms. There is strong evidence that VIMS can occur in the absence of vection (Ji et al., 2009). Other studies have presented evidence that suggests a negative relationship between vection and CS (Bonato et al., 2008; Palmisano et al., 2017). Palmisano et al. (2017) recently found that individuals who felt stronger vection (magnitude estimates) were likely to report fewer symptoms of CS (SSQ). This effect was dependent on the visual display conditions: The relationship was only obtained when visual stimuli were observed through a simulated aperture (field-of-view: $86^{\circ}$ diagonal), and not when participants observed a "full field" stimulus (field-of-view: $110^{\circ}$ diagonal). The authors reiterated that the link between vection and CS was relatively weak, and that a complex relationship is likely to exist. In several other experiments, there appeared to be no association between VIMS and vection (Webb and Griffin, 2003; Keshavarz and Hecht, 2011a; Riecke and Jordan, 2015). Evidently, there are highly complex relationships between vection and CS, as well as between vection and presence. This complexity has been discussed by others who suggest that vection poses an intervening factor between presence and CS (Stanney et al., 1998; Sadowski and Stanney, 2002; Hettinger et al., 2014). Concurrent measurements of each variable will be essential in 
future research studies attempting to model the presence-CSvection relationship.

\section{Intuitiveness of Interaction}

Presence has been termed the illusion of a non-mediated experience (Lombard and Ditton, 1997). This illusion is encompassed by the absence of attention to the apparatuses used to convey a simulation, such as the visual display device itself, the environmental boundaries, and the controls used to interact with the environment. For this reason, natural (ecological) control methods that do not distract from the simulation are likely to produce higher presence. Examples of this principle were provided by Welch et al. (1996), who indicated that the ability to interact with the environment increases presence, and that increasing the latency between action and feedback can negatively impact presence. Additionally, Schuemie et al. (2005) showed that more "natural" locomotion techniques (i.e., walking in place compared with mouse navigation) lead to a greater sense of presence (IPQ). Equally, the intuitiveness of the control scheme in VR has been linked to CS rates, with a greater degree of CS provoked by less ecological control schemes. For instance, Kolasinski (1995) discusses that freezing or resetting the simulated viewpoint of an observer tends to be highly nauseogenic. Borrego et al. (2016) report that navigating a virtual environment by walking leads to increased levels of presence (SUS and PQ) compared with using a hand-held controller to navigate. Additionally, Jaeger and Mourant (2001) documented that navigating by walking on a treadmill led to significantly lower CS severity (SSQ) than when a hand-held controller was used. These series of findings are perhaps unsurprising, given that exposure to novel sensorimotor conditions in the real world is known to provoke sickness (e.g., prism glasses that reverse the orientation of the visual field are initially nauseogenic for users, Oman, 1991). However, some research has indicated that more intuitive controls do not affect CS (e.g., Borrego et al., 2016), or can even lead to an increase in CS (e.g., the addition of head tracking in the study of Schuemie et al. (2005), led to an increase in SSQ scores), although this may be related to the small sensory mismatches introduced by imperfect tracking conditions in these cases. It appears likely that presence and comfort are both reduced when interacting with a virtual environment in a manner that is unfamiliar in terms of sensorimotor control. As such, results of experiments that manipulate the control scheme in VR may tend to suggest a negative relationship between CS and presence due to the inverse effect of sensorimotor familiarity on each factor.

\section{Navigation Control}

The capability of action within a virtual environment has frequently been linked to the feeling of presence in VR (e.g., Sanchez-Vives and Slater, 2005; Slater, 2009), and in line with this idea there is evidence that controlling one's own locomotion in a virtual landscape increases presence (Stanney et al., 2002; Clemente et al., 2014). There is also a long history of research documenting the nauseating effects of being moved passively in VR and driving simulators (Rolnick and Lubow, 1991; Stanney and Hash, 1998; Sharples et al., 2008; Dong et al., 2011). Predictive movement control allows a user to compare estimated and obtained sensory data in a feedforward control loop, which is thought to reduce the impact of decoupling efferent and afferent signals (Reason and Brand, 1975; Rolnick and Lubow, 1991).

As part of a study by Seay et al. (2002) (described above), the authors investigated the effect of being the driver or the passenger in a driving simulation. Enacting the role of the driver increases the sense of presence (PQ). At the same time, the magnitude of CS was higher for passengers compared to drivers (SSQ), as found in other research (Rolnick and Lubow, 1991; Stanney and Hash, 1998; Sharples et al., 2008; Dong et al., 2011).

Results of a recent study have indicated that navigation in a virtual landscape (i.e., locomotion using an Xbox 360 Gamepad) increases presence (SUS) compared to conditions where participants remained relatively stationary (head tracking and motion parallax, but no locomotion), but that sickness scores (SSQ) are unaffected by the same manipulation (Ibánez and Peinado, 2016). This suggests that presence increases when participants are permitted to freely explore an environment, even if the navigation method used is relatively unnatural (i.e., navigating with a gamepad). However, the manipulation used by the authors cannot discern whether other mediating variables might have played a role, such as optic flow or vection produced by locomotion.

\section{Context}

Narrative is often used to provide context and framing to a VR application, and there is evidence that the inclusion of narrative impacts both presence and CS. The influence of a "preamble" on presence has recently been established (Smolentsev et al., 2017): When participants initiate a VR task in a digital environment similar to their own physical location, the sense of presence (single item scale) increased significantly compared to when the digital environment portrayed a different physical location. The authors stated that the benefit of a familiar environment on the sense of presence is achieved by establishing a physical continuity between the user's experience in the real environment and the virtual landscape.

The effect of context on presence has been frequently studied with respect to the mediating effect of anxiety on presence. There is thought to be a complex, potentially bi-directional relationship between presence and anxiety, with both being associated with general sympathetic nervous system activity (Rothbaum and Hodges, 1999; Krijn et al., 2004). Gorini et al. (2011) show a heightened sense of presence (SUS) if an anxiety-inducing narrative context was provided while the participant searched for an object in VR (i.e., the participant was being "chased" by a "murderous" person as they searched). A significant increase in presence (single item scale) also occurs if participants with a phobia are told that the virtual environment may contain a phobic stimulus (Bouchard et al., 2008). On the other hand, the use of a different measurement scale (PQ) has resulted in the opposite trend: Anxiety-inducing narrative context produced a reduction in total presence (Bouchard et al., 2008). Although the authors attributed this divergence in results to one or two items in the PQ dominating their results, this provides further evidence for a low level of reliability between common measures 
of presence. The effect of anxiolytic narrative on CS (SSQ) was also measured by Bouchard et al. (2008), with the authors finding no relationship between the two variables. A similar pattern of results was obtained by Robillard et al. (2003), who found a relationship between presence and anxiety (both single item scales) but no link between either factor and CS (SSQ), although CS scores were overall very low. The absence of a link between CS and anxiety is somewhat surprising, given that trait-anxiety measures partially determine the likelihood of motion sickness in the general population (Paillard et al., 2013), and as such future studies will need to investigate this link further.

\section{Sex}

There has been considerable discussion about the effects of participant sex on presence ratings. Some have theorized that the degree to which men and women can suspend disbelief may vary (Slater and Usoh, 1994; Felnhofer et al., 2012), along with personality factors such as extraversion and submissiveness (Lombard and Ditton, 1997). Others have proposed that any sex effects on presence are likely due to the correlated differences in gaming experience between the sexes (Gamito et al., 2008, 2010). However, the empirical research is divided with respect to which sex demonstrates higher levels of presence. In an anxietyinducing VR environment (a school examination), Gamito et al. (2008) reported evidence of a higher level of presence for women than for men (PQ realism), although the authors attributed this effect to the higher experience with video games among male participants. On the other hand, other studies have found that men report higher levels of presence than women in VR (Slater et al., 1998; Nicovich et al., 2005) and in non-VR video games (Lachlan and Krcmar, 2011). Felnhofer et al. (2012) documented evidence of a sex effect on presence ratings (IPQ spatial presence), with men rating themselves higher than women. Other research has found no difference between men and women with respect to spatial presence (De Leo et al., 2014).

Research into CS has long discussed the possibility of sex differences with respect to rates of susceptibility, although findings have proven inconclusive. In the work of Knight and Arns (2006); Gamito et al. (2008), and Ling et al. (2013) described elsewhere here, the authors failed to identify any difference in CS across the sexes. Conversely, studies by De Leo et al. (2014) and Jaeger and Mourant (2001) revealed that female participants were significantly more likely to experience CS symptoms than male participants. In a similar vein, Park et al. (2006) reported that non-dropout female participants exhibited more CS symptoms (SSQ nausea and oculomotor subscales) than male participants did in a non-immersive driving simulator. Häkkinen et al. (2002) also found CS ratings (SSQ) were lower for men than for women. Some have also suggested that the reason for the discordant findings on sex and CS may relate to hormonal changes across the menstrual cycle, resulting in a fluctuating relationship (Biocca, 1992; Clemes and Howarth, 2005).

\section{Gaming Experience}

Some research has examined the influence of past experience with interactive games on factors such as presence and CS. Knight and Arns (2006) identified an inverse association between an individual's experience playing video games and the level of CS experienced. Various studies report no relationship between presence and gameplay experience (Schuemie et al., 2005; Alsina-Jurnet and Gutiérrez-Maldonado, 2010; Ling et al., 2013). Others have found minimal evidence for an effect of video game experience on presence ratings or CS. Gamito et al. (2010) experimentally manipulated gameplay experience using a training procedure, and reported that increased gaming experience leads to improved presence (PQ) whereas CS (SSQ) was unaffected by training. In another study that employed a similar task, Gamito et al. (2008) found no relationship between measures of presence (PQ, ITQ) or CS (SSQ) and the previous gameplay experience of participants. At the same time, the authors found an increase in physiological markers of heart rate with increasing experience with video games. Those authors considered heart rate as a measure of anxiety, but we note that others have taken similar markers to indicate presence (e.g., Meehan et al., 2001, 2003; Wiederhold et al., 2001) and also CS (e.g., Kim et al., 2005; Dennison et al., 2016). Accordingly, one should be cautious when interpreting physiological markers purported to measure these factors given the relative paucity and inconsistency of data of this sort reported to date.

\section{Conclusion: Associated Variables}

When taken together, the evidence obtained from the review above begins to clarify the type of relationship that exists between presence and CS:

- Approaches that reduce sensory mismatch show potential for reducing CS and increasing presence;

- Both presence and CS are increased by the addition of stereoscopy, high field-of-view display conditions, and by enhancing the likelihood that a display will evoke vection;

- Increasing factors such as intuitiveness of interaction and control of navigation lead to higher presence and lower CS;

- Men and individuals with more gaming experience demonstrate lower CS and higher presence, although the partial effects of sex and gaming are not fully clear.

The relationship between CS and presence can be understood if the associated variables described above are considered with respect to their effect on sensory mismatch. Immersiveness (sensory submersion) likely plays a key role here: Experimental manipulations that increase immersiveness tend to produce both CS and presence, because the compelling nature of stimuli in an immersive virtual space fosters a high perceptual weighting of cues to self-motion and spatial orientation, which enhances the impact of conflicts between expected and obtained sensory signals that are generated by the compelling stimulus (Prothero, 1998; Lombard et al., 2000; Prothero and Parker, 2003). Put differently, immersiveness enhances the magnitude of violated expectations. Thus, increasing field-of-view size, adding stereoscopy, or providing congruent multisensory information can increase both presence and CS. Given that immersiveness (which increases the weight of sensory conflicts, Prothero, 1998) can also lead to increased vection (which is inversely related to sensory conflicts, e.g., Weech and Troje, 2017) 
it is unsurprising that research on the vection-presence-CS relationship has concluded that the link is extremely complex (Keshavarz et al., 2015; Palmisano et al., 2017).

On the other hand, within immersive conditions, individuals who experience high presence tend to experience low levels of CS. This relationship may be a result of differences in individual sensitivity to sensory conflicts: Higher sensitivity will result in high CS and low presence, whereas low sensitivity to cue conflicts will lead to low levels of CS and a heightened sense of presence. Individual differences in sensitivity to sensory conflicts have been documented, and there is some limited evidence that these differences relate to CS and presence (Viaud-Delmon et al., 2000, 2006). The advantage in terms of presence and CS observed for "gamers" may be attributed to the process of sensory reweighting that occurs during continuous exposure to cue conflicts (see Reason and Brand, 1975; Weech et al., 2018a). Indeed, a sex effect on presence and CS possibly relates to the superior ability of men to adapt to sensory conflicts compared with women (Viaud-Delmon et al., 1998). Further research on these individual differences will be required in order to test the proposition that variance in sensory conflict sensitivity underlies the experience of both presence and CS.

There is a significant challenge involved in identifying the factors that might mediate the link between presence and CS. Primarily this difficulty arises from the substantial relationships between the associated factors identified above, such as sex and gameplay experience, or vection and field-of-view. In addition to these known relationships, a number of other understudied variables may have significant associations with both presence and CS. For instance, the sense of embodiment is known to form a core aspect of presence (Kilteni et al., 2012), but the relationship between the embodiment of a virtual body and CS is currently unclear. Furthermore, questions remain about how prior experience with VR systems interacts with presence and CS; experiential factors are currently understudied due to the novelty of widely available VR technology. It is also evident that there is a lack of research that combines measurements of presence, $\mathrm{CS}$, and other factors in high-powered studies. The collection of large datasets that encompass multiple individual factors (age, sex, personality type) with several behavioral response measures (objective and subjective measures of presence and CS) permits the use of a modeling approach that would enhance our understanding of the complex relationship between presence, CS, and other mediating factors (a similar approach was adopted for CS alone in Weech et al., 2018b). Through the execution of such studies in the future, further interactions will be uncovered between the associated factors outlined above.

Questions remain with regard to what questionnaires of presence and CS are truly measuring. Studies have identified relationships between CS and spatial presence, but no relationship between CS and immersive tendencies, which correlates highly with spatial presence (e.g., Ling et al., 2013). This raises the problem that the degree to which an individual's tendency to report feeling presence or CS may not determine their experience of either factor. This is an inherent issue in questionnaire studies; according to a meta-analysis, almost $50 \%$ of questionnaire studies documented effects of social desirability on their results (Van de Mortel, 2008). It is therefore important that future research takes into account the possibility that response bias modulates measures of factors like presence and CS. Several approaches could be adopted to achieve this, including pre-task questionnaires that assess social desirability (Crowne and Marlowe, 1960; Van de Mortel, 2008) or developing and using questionnaires according to principles of minimizing bias (Choi and Pak, 2005).

\section{GENERAL CONCLUSION AND FUTURE DIRECTIONS}

Literature supports the idea that presence and CS are inversely related, and that the relationship is likely to be mediated by factors including vection, navigation control, and display factors. These factors can be unified in terms of their effect on sensory mismatch, which appears to drive presence and CS in opposite directions. This presents the possibility that interventions targeted at increasing presence could reduce CS, and vice versa. While the results obtained across studies are often discordant, with many sources reporting a positive relationship between presence and CS, these outcomes may be related to the fact that immersive displays are likely to generate both a compelling sense of "being there," as well as symptoms of physiological discomfort. Other noise sources that may contribute to variability in findings include problematic measurement techniques, or differences in the operational definition of the underlying factors among studies.

How can future experimentation best serve the advancement of our understanding of the presence-CS association? The issue of measurement validity must be a major focus of future studies, where the cross-validation of metrics should be undertaken in well-controlled paradigms. Improving the robustness of findings in this area may also require a careful consideration of factors that could play a role in response bias, such as social desirability. Although a limited number of high quality studies have collected large datasets related to human factors in VR, future experiments will need to combine these measures with a modeling approach that can help to interpret the structure of the relationship between these factors. Relatedly, there is a prevalent lack of statistical power in many of the studies reviewed here, and this limits the ability for the field to infer answers about variables that are so inherently noisy. Future studies will benefit from careful $a$ priori considerations of effect sizes, which we have compiled here where available. An additional factor that may reduce the variability in findings across future studies is the natural emergence of standardized VR head-mounted hardware. Note, however, that the findings of studies using lower-immersive systems such as projection screens will still prove valuable, as these will help to identify the impact of immersiveness and vergenceaccommodation mismatch on CS and presence. One particular gap in our understanding revealed by the current review is how presence is affected when sensory mismatch is experimentally manipulated. Given the prospective modulatory role of sensory mismatch in the association between presence and CS, future studies will need to overcome the challenges in manipulating 
and assessing sensory mismatch in empirical research. Through a careful consideration of the literature critique provided here, we envisage that the next wave of studies on the presence-CS link will help to make major advances toward understanding this complex relationship.

\section{AUTHOR CONTRIBUTIONS}

SW, SK, and MB-C designed the concept of the article and conducted revisions to the manuscript. SW and SK

\section{REFERENCES}

Aardema, F., O'Connor, K., Côté, S., and Taillon, A. (2010). Virtual reality induces dissociation and lowers sense of presence in objective reality. Cyberpsychol. Behav. Soc. Netw. 13, 429-435. doi: 10.1089/cyber.2009.0164

Alsina-Jurnet, I., and Gutiérrez-Maldonado, J. (2010). Influence of personality and individual abilities on the sense of presence experienced in anxiety triggering virtual environments. Int. J. Hum. Comput. Stud. 68, 788-801. doi: 10.1016/j. ijhcs.2010.07.001

Bailenson, J. N., Aharoni, E., Beall, A. C., Guadagno, R. E., Dimov, A., and Blascovich, J. (2004). "Comparing behavioral and self-report measures of embodied agents' social presence in immersive virtual environments," in Proceedings of the 7th Annual International Workshop on Presence, (Spain: Technical University of Valencia).

Balaban, C. D., Starcević, V. P., and Severs, W. B. (1989). Neuropeptide modulation of central vestibular circuits. Pharmacol. Rev. 41, 53-90.

Bangay, S., and Preston, L. (1998). An investigation into factors influencing immersion in interactive virtual reality environments. Stud. Health Technol. Inform. 58, 43-51.

Barfield, W., Zeltzer, D., Sheridan, T., and Slater, M. (1995). "Presence and performance within virtual environments," in Virtual Environments and Advanced Interface Design, eds W. Barfield and T. A. Furness (Oxford: Oxford University Press), 473-513.

Baumgartner, T., Speck, D., Wettstein, D., Masnari, O., Beeli, G., and Jäncke, L. (2008). Feeling present in arousing virtual reality worlds: prefrontal brain regions differentially orchestrate presence experience in adults and children. Front. Hum. Neurosci. 2:8. doi: 10.3389/neuro.09.008.2008

Baumgartner, T., Valko, L., Esslen, M., and Jäncke, L. (2006). Neural correlate of spatial presence in an arousing and noninteractive virtual reality: an EEG and psychophysiology study. Cyberpsychol. Behav. 9, 30-45. doi: 10.1089/cpb. 2006.9.30

Baus, O., and Bouchard, S. (2017). Exposure to an unpleasant odour increases the sense of presence in virtual reality. Virtual Real. 21, 59-74. doi: 10.1007/s10055016-0299-3

Biocca, F. (1992). Will simulation sickness slow down the diffusion of virtual environment technology? Presence Teleoper. Virtual Environ. 1, 334-343. doi: 10.1162/pres.1992.1.3.334

Biocca, F., and Delaney, B. (1995). "Immersive virtual reality technology," in Communication in the Age of Virtual Reality, eds F. Biocca and M. R. Levy (Oxfordshire: Taylor \& Francis), 57-127.

Biocca, F., Harms, C., and Burgoon, J. K. (2003). Toward a more robust theory and measure of social presence: review and suggested criteria. Presence Teleoper. Virtual Environ. 12, 456-480. doi: 10.1162/105474603322761270

Bonato, F., Bubka, A., Palmisano, S., Phillip, D., and Moreno, G. (2008). Vection change exacerbates simulator sickness in virtual environments. Presence Teleoper. Virtual Environ. 17, 283-292. doi: 10.1162/pres.17.3.283

Borrego, A., Latorre, J., Llorens, R., Alcañiz, M., and Noé, E. (2016). Feasibility of a walking virtual reality system for rehabilitation: objective and subjective parameters. J. Neuroeng. Rehabil. 13:68. doi: 10.1186/s12984-016-0174-1

Bos, J. E., MacKinnon, S. N., and Patterson, A. (2005). Motion sickness symptoms in a ship motion simulator: effects of inside, outside, and no view. Aviat. Space Environ. Med. 76, 1111-1118. conducted the literature search. SW wrote the initial draft of the article.

\section{FUNDING}

This research was supported by grants from Oculus Research and the Natural Sciences and Engineering Research Council of Canada (NSERC) [(Grant no. RGPIN-05435-2014)] awarded to MB-C. The funding sources had no input in the preparation of the manuscript.

Bouchard, S., Robillard, G., St-Jacques, J., Dumoulin, S., Patry, M. J., and Renaud, P. (2004). "Reliability and validity of a single-item measure of presence in VR," in Proceedings of The 3rd IEEE International Workshop on Haptic, Audio and Visual Environments and Their Applications, HAVE, (Piscataway, NY: IEEE), 59-61. doi: 10.1109/HAVE.2004.1391882

Bouchard, S., St-Jacques, J., Robillard, G., and Renaud, P. (2008). Anxiety increases the feeling of presence in virtual reality. Presence Teleoper. Virtual Environ. 17, 376-391. doi: 10.1162/pres.17.4.376

Bowman, D. A., and McMahan, R. P. (2007). Virtual reality: how much immersion is enough? Computer 40, 36-43. doi: 10.1109/MC.2007.257

Brooks, J. X., and Cullen, K. E. (2013). The primate cerebellum selectively encodes unexpected self-motion. Curr. Biol. 23, 947-955. doi: 10.1016/j.cub.2013.04.029

Brooks, J. X., and Cullen, K. E. (2014). Early vestibular processing does not discriminate active from passive self-motion if there is a discrepancy between predicted and actual proprioceptive feedback. J. Neurophysiol. 111, 2465-2478. doi: 10.1152/jn.00600.2013

Busscher, B., De Vliegher, D., Ling, Y., and Brinkman, W. P. (2011). Physiological measures and self-report to evaluate neutral virtual reality worlds. J. Cyberther. Rehabil. 4, 1-18.

Button, K. S., Ioannidis, J. P., Mokrysz, C., Nosek, B. A., Flint, J., Robinson, E. S., et al. (2013). Power failure: why small sample size undermines the reliability of neuroscience. Nat. Rev. Neurosci. 14, 365-376. doi: 10.1038/nrn3475

Calvert, G., Spence, C., and Stein, B. E. (eds) (2004). The Handbook of Multisensory Processes. Cambridge, MA: MIT Press.

Cevette, M. J., Stepanek, J., Cocco, D., Galea, A. M., Pradhan, G. N., Wagner, L. S., et al. (2012). Oculo-vestibular recoupling using galvanic vestibular stimulation to mitigate simulator sickness. Aviat. Space Environ. Med. 83, 549-555. doi: 10.3357/ASEM.3239.2012

Chertoff, D. B., and Schatz, S. L. (2014). "Beyond presence: how holistic experience drives training and education," in Handbook of Virtual Environments: Design, Implementation, and Applications, eds K. S. Hale and K. M. Stanney (Boca Raton, FL: CRC Press), 857-872.

Choi, B. C., and Pak, A. W. (2005). Peer reviewed: a catalog of biases in questionnaires. Prev. Chronic Dis. 2:A13.

Clemente, M., Rey, B., Rodríguez-Pujadas, A., Barros-Loscertales, A., Baños, R. M., Botella, C., et al. (2013). An fMRI study to analyze neural correlates of presence during virtual reality experiences. Interact. Comput. 26, 269-284. doi: 10.1093/ iwc/iwt037

Clemente, M., Rodríguez, A., Rey, B., and Alcañiz, M. (2014). Assessment of the influence of navigation control and screen size on the sense of presence in virtual reality using EEG. Expert Syst. Appl. 41, 1584-1592. doi: 10.1016/j.eswa. 2013.08.055

Clemes, S. A., and Howarth, P. A. (2005). The menstrual cycle and susceptibility to virtual simulation sickness. J. Biol. Rhythms 20, 71-82. doi: 10.1177/ 0748730404272567

Cobb, S. V., Nichols, S., Ramsey, A., and Wilson, J. R. (1999). Virtual realityinduced symptoms and effects (VRISE). Presence Teleoper. Virtual Environ. 8, 169-186. doi: 10.1162/105474699566152

Cobb, S. V., Nichols, S., and Wilson, J. R. (1995). "Health and safety implications of virtual reality: in search of an experimental methodology," in Proceedings of the FIVEi95 (Framework for Immersive Virtual Environments), (London: University of London), 227-242. 
Cooper, N., Milella, F., Cant, I., Pinto, C., White, M. D., and Meyer, G. F. (2016). The effects of multisensory cues on the sense of presence and task performance in a virtual reality environment. Perception 45, 332-333.

Corrêa, A. G., Borba, E. Z., Lopes, R., Zuffo, M. K., Araujo, A., and Kopper, R. (2017). "User experience evaluation with archaeometry interactive tools," in Proceedings of the IEEE Symposium on Virtual Reality Environment, 3D User Interfaces (3DUI), March 2017, (Piscataway, NJ: IEEE), 217-218. doi: 10.1109/ 3DUI.2017.7893349

Crowne, D. P., and Marlowe, D. (1960). A new scale of social desirability independent of psychopathology. J. Consult. Psychol. 24, 349-354. doi: 10.1037/ h0047358

Cummings, J. J., and Bailenson, J. N. (2016). How immersive is enough? A metaanalysis of the effect of immersive technology on user presence. Media Psychol. 19, 272-309. doi: 10.1080/15213269.2015.1015740

Dalgarno, B., and Lee, M. J. (2010). What are the learning affordances of 3-D virtual environments? Br. J. Educ. Technol. 41, 10-32. doi: 10.1111/j.1467-8535.2009. 01038.x

Davis, S., Nesbitt, K., and Nalivaiko, E. (2014). "A systematic review of cybersickness," in Proceedings of the 2014 Conference on Interactive Entertainment, (New York, NY: ACM), 1-9. doi: 10.1145/2677758.2677780

De Leo, G., Diggs, L. A., Radici, E., and Mastaglio, T. W. (2014). Measuring sense of presence and user characteristics to predict effective training in an online simulated virtual environment. Simul. Healthc. 9, 1-6. doi: 10.1097/SIH. 0b013e3182a99dd9

Dennison, M. S., Wisti, A. Z., and D’Zmura, M. (2016). Use of physiological signals to predict cybersickness. Displays 44, 42-52. doi: 10.1016/j.displa.2016.07.002

DiZio, P., and Lackner, J. R. (1997). “August. Circumventing side effects of immersive virtual environments," in Design of Computing Systems: Social and Ergonomic Considerations, eds M. Smith, G. Salvendy, and R. Koubek (Amsterdam: Elsevier Science), 893-896.

Dong, X., Yoshida, K., and Stoffregen, T. A. (2011). Control of a virtual vehicle influences postural activity and motion sickness. J. Exp. Psychol. Appl. 17, 128-138. doi: 10.1037/a0024097

Emoto, M., Nojiri, Y., and Okano, F. (2004). Changes in fusional vergence limit and its hysteresis after viewing stereoscopic TV. Displays 25, 67-76. doi: 10.1016/j. displa.2004.07.001

Eversmann, T., Gottsmann, M., Uhlich, E., Ulbrecht, G., Werder, K. V., and Scriba, P. C. (1978). Increased secretion of growth hormone, prolactin, antidiuretic hormone, and cortisol induced by the stress of motion sickness. Aviat. Space Environ. Med. 1, 53-57.

Felnhofer, A., Kothgassner, O. D., Beutl, L., Hlavacs, H., and Kryspin-Exner, I. (2012). "Is virtual reality made for men only? Exploring gender differences in the sense of presence," in Proceedings of the International Society on Presence Research, Philadelphia, PA, 103-112.

Frank, L. H., Casali, J. G., and Wierwille, W. W. (1988). Effects of visual display and motion system delays on operator performance and uneasiness in a driving simulator. Hum. Factors 30, 201-217. doi: 10.1177/001872088803000207

Gálvez-García, G., Hay, M., and Gabaude, C. (2015). Alleviating simulator sickness with galvanic cutaneous stimulation. Hum. Factors 57, 649-657. doi: 10.1177/ 0018720814554948

Gamito, P., Oliveira, J., Morais, D., Baptista, A., Santos, N., Soares, F., et al. (2010). Training presence: the importance of virtual reality experience on the "sense of being there". Ann. Rev. Cyberther. Telemed. 2010, 128-133.

Gamito, P., Oliveira, J., Santos, P., Morais, D., Saraiva, T., Pombal, M., et al. (2008). Presence, immersion and cybersickness assessment through a test anxiety virtual environment. Ann. Rev. Cyberther. Telemed. 2008, 83-90.

Gavgani, A. M., Nesbitt, K. V., Blackmore, K. L., and Nalivaiko, E. (2017). Profiling subjective symptoms and autonomic changes associated with cybersickness. Auton. Neurosci. 203, 41-50. doi: 10.1016/j.autneu.2016.12.004

Glover, J. C. (2009). "Vestibular system," in Encyclopedia of Neuroscience, eds L. R. Squire, N. F. Dronkers, and J. V. Baldo (Amsterdam: Elsevier), 127-132.

Golding, J. F. (1992). Phasic skin conductance activity and motion sickness. Aviat. Space Environ. Med. 63, 165-171.

Gorini, A., Capideville, C. S., De Leo, G., Mantovani, F., and Riva, G. (2011). The role of immersion and narrative in mediated presence: the virtual hospital experience. Cyberpsychol. Behav. Soc. Netw. 14, 99-105. doi: 10.1089/cyber. 2010.0100
Grabarczyk, P., and Pokropski, M. (2016). Perception of affordances and experience of presence in virtual reality. AVANT 3, 25-44. doi: 10.3389/fpsyg. 2015.01944

Häkkinen, J., Vuori, T., and Paakka, M. (2002). "Postural stability and sickness symptoms after HMD use," in IEEE International Conference on Systems, Man and Cybernetics, Vol. 1, (Yasmine Hammamet: IEEE), 147-152. doi: 10.1109/ ICSMC.2002.1167964

Harm, D. L. (2002). "Motion sickness neurophysiology, physiological correlates, and treatment," in Handbook of Virtual Environments: Design, Implementation, and Applications, ed. K. M. Stanney (Boca Raton FL: CRC Press), 637-661.

Hecht, D., Reiner, M., and Halevy, G. (2006). Multimodal virtual environments: response times, attention, and presence. Presence Teleoper. Virtual Environ. 15, 515-523. doi: 10.1162/pres.15.5.515

Heeter, C. (1992). Being there: the subjective experience of presence. Presence Teleoper. Virtual Environ. 1, 262-271. doi: 10.1162/pres.1992.1.2.262

Henderson, A., Korner-Bitensky, N., and Levin, M. (2007). Virtual reality in stroke rehabilitation: a systematic review of its effectiveness for upper limb motor recovery. Top. Stroke Rehabil. 14, 52-61. doi: 10.1310/tsr1402-52

Herbelin, B., Salomon, R., Serino, A., and Blanke, O. (2015). "Neural mechanisms of bodily self-consciousness and the experience of presence in virtual reality," in Human Computer Confluence, eds A. Gaggioli, A. Ferscha, G. Riva, S. Dunne, and I. Viaud-Delmon (Berlin: Human Computer Confluence), 80-96.

Hettinger, L. J., Berbaum, K. S., Kennedy, R. S., Dunlap, W. P., and Nolan, M. D. (1990). Vection and simulator sickness. Mil. Psychol. 2, 171-181. doi: 10.1207/ s15327876mp0203_4

Hettinger, L. J., and Riccio, G. E. (1992). Visually induced motion sickness in virtual environments. Presence Teleoper. Virtual Environ. 1, 306-310. doi: 10.1162/ pres.1992.1.3.306

Hettinger, L. J., Schmidt-Daly, T. N., Jones, D. L., and Keshavarz, B. (2014). "Illusory self-motion in virtual environments," in Handbook of Virtual Environments: Design, Implementation, and Applications, eds K. S. Hale and K. M. Stanney (Boca Raton FL: CRC Press), 435-467. doi: 10.1201/b173 60-23

Ibánez, M. L., and Peinado, F. (2016). "Walking in vr: measuring presence and simulator sickness in first-person virtual reality games," in Proceedings of the Third Congress of the Spanish Society for Video Games Sciences, (Barcelona).

IJsselsteijn, W., de Ridder, H., Freeman, J., Avons, S. E., and Bouwhuis, D. (2001). Effects of stereoscopic presentation, image motion, and screen size on subjective and objective corroborative measures of presence. Presence Teleoper. Virtual Environ. 10, 298-311. doi: 10.1162/105474601300343621

IJsselsteijn, W. A., de Ridder, H., Freeman, J., and Avons, S. E. (2000). "June. Presence: concept, determinants, and measurement," in Human Vision and Electronic Imaging, Vol. 3959, (Bellingham, WA: International Society for Optics and Photonics), 520-530.

Jaeger, B. K., and Mourant, R. R. (2001). "Comparison of simulator sickness using static and dynamic walking simulators," in Proceedings of the Human Factors and Ergonomics Society Annual Meeting, Vol. 45, (Sage CA: SAGE Publications), 1896-1900. doi: 10.1177/154193120104502709

Ji, J. T., So, R. H., and Cheung, R. T. (2009). Isolating the effects of vection and optokinetic nystagmus on optokinetic rotation-induced motion sickness. Hum. Factors 51, 739-751. doi: 10.1177/0018720809349708

Jones, M. B., Kennedy, R. S., and Stanney, K. M. (2004). Toward systematic control of cybersickness. Presence Teleoper. Virtual Environ. 13, 589-600. doi: 10.1162/ 1054746042545247

Jones, S. (2000). Towards a philosophy of virtual reality: issues implicit in "consciousness reframed". Leonardo 33, 125-132. doi: 10.1162/ 002409400552388

Kennedy, R. S., and Fowlkes, J. E. (1992). Simulator sickness is polygenic and polysymptomatic: implications for research. Int. J. Aviat. Psychol. 2, 23-38. doi: 10.1207/s15327108ijap0201_2

Kennedy, R. S., Lane, N. E., Berbaum, K. S., and Lilienthal, M. G. (1993). Simulator sickness questionnaire: An enhanced method for quantifying simulator sickness. Int. J. Aviat. Psychol. 3, 203-220. doi: 10.1207/s15327108ijap0303_3

Keshavarz, B., and Hecht, H. (2011a). Axis rotation and visually induced motion sickness: the role of combined roll, pitch, and yaw motion. Aviat. Space Environ. Med. 82, 1023-1029.

Keshavarz, B., and Hecht, H. (2011b). Validating an efficient method to quantify motion sickness. Hum. Factors 53, 415-426. 
Keshavarz, B., and Hecht, H. (2012). Stereoscopic viewing enhances visually induced motion sickness but sound does not. Presence Teleoper. Virtual Environ. 21, 213-228. doi: 10.1162/PRES_a_00102

Keshavarz, B., Hettinger, L. J., Kennedy, R. S., and Campos, J. L. (2014). Demonstrating the potential for dynamic auditory stimulation to contribute to motion sickness. PLoS One 9:e101016. doi: 10.1371/journal.pone.0101016

Keshavarz, B., Riecke, B. E., Hettinger, L. J., and Campos, J. L. (2015). Vection and visually induced motion sickness: how are they related? Front. Psychol. 6:472. doi: 10.3389/fpsyg.2015.00472

Kilteni, K., Groten, R., and Slater, M. (2012). The sense of embodiment in virtual reality. Presence Teleoper. Virtual Environ. 21, 373-387. doi: 10.1162/PRES_a_ 00124

Kim, J., Palmisano, S., and Bonato, F. (2012). Simulated angular head oscillation enhances vection in depth. Perception 41, 402-414. doi: 10.1068/p6919

Kim, K., Rosenthal, M. Z., Zielinski, D., and Brady, R. (2012). “Comparison of desktop, head mounted display, and six wall fully immersive systems using a stressful task," in Paper Presented at the Virtual Reality Short Papers and Posters (VRW), (Piscataway, NJ: IEEE), 143-144. doi: 10.1109/VR.2012.6180922

Kim, M. S., Chey, W. D., Owyang, C., and Hasler, W. L. (1997). Role of plasma vasopressin as a mediator of nausea and gastric slow wave dysrhythmias in motion sickness. Am. J. Physiol. Gastrointest. Liver Physiol. 272, G853-G862. doi: 10.1152/ajpgi.1997.272.4.G853

Kim, Y. Y., Kim, H. J., Kim, E. N., Ko, H. D., and Kim, H. T. (2005). Characteristic changes in the physiological components of cybersickness. Psychophysiology 42, 616-625. doi: 10.1111/j.1469-8986.2005.00349.x

Kinsella, A. J. (2014). The Effect of $0.2 \mathrm{~Hz}$ and $1.0 \mathrm{~Hz}$ Frequency and $100 \mathrm{~ms}$ and 20100 ms Amplitude of Latency on Simulatory Sickness in a Head Mounted Display. Ph.D. thesis, Clemson University, Clemson, SC.

Klosterhalfen, S., Kellermann, S., Pan, F., Stockhorst, U., Hall, G., and Enck, P. (2005). Effects of ethnicity and gender on motion sickness susceptibility. Aviat. Space Environ. Med. 76, 1051-1057.

Knight, M. M., and Arns, L. L. (2006). The relationship among age and other factors on incidence of cybersickness in immersive environment users. Paper Presented at the ACM Siggraph 2006 Research Posters, (New York, NY: ACM), 196. doi: $10.1145 / 1179622.1179846$

Kober, S. E., and Neuper, C. (2012). Using auditory event-related EEG potentials to assess presence in virtual reality. Int. J. Hum. Comput. Stud. 70, 577-587. doi: 10.1016/j.ijhcs.2012.03.004

Kohl, R. L. (1985). Endocrine correlates of susceptibility to motion sickness. Aviat. Space Environ. Med. 56, 1158-1165.

Kolasinski, E. M. (1995). Simulator Sickness in Virtual Environments (No. ARI-TR1027). Alexandria, VA: Army Research Institute for the Behavioral and Social Sciences. doi: 10.21236/ADA295861

Krijn, M., Emmelkamp, P. M., Olafsson, R. P., and Biemond, R. (2004). Virtual reality exposure therapy of anxiety disorders: a review. Clin. Psychol. Rev. 24, 259-281. doi: 10.1016/j.cpr.2004.04.001

Krueger, M. (1992). Artificial Reality, 2nd Edn. Rexling, MA: Addison-Wesley.

Lachlan, K., and Krcmar, M. (2011). Experiencing presence in video games: the role of presence tendencies, game experience, gender, and time spent in play. Commun. Res. Rep. 28, 27-31. doi: 10.1080/08824096.2010.518924

Lambooij, M., IJsselsteijn, W., Bouwhuis, D. G., and Heynderickx, I. (2011). Evaluation of stereoscopic images: beyond 2D quality. IEEE Trans. Broadcast. 57, 432-444. doi: 10.1109/TBC.2011.2134590

Larsson, P., Vastfjall, D., and Kleiner, M. (2002). "Better presence and performance in virtual environments by improved binaural sound rendering," in Proceedings of the 22nd International Conference of Virtual, Synthetic, and Entertainment Audio, June 2002, (New York, NY: Audio Engineering Society).

LaViola, J. J. Jr. (2000). A discussion of cybersickness in virtual environments. ACM SIGCHI Bull. 32, 47-56. doi: 10.1145/333329.333344

Lee, K. M. (2004). Presence, explicated. Commun. Theory 14, 27-50. doi: 10.1111/ j.1468-2885.2004.tb00302.x

Lerman, Y. S. G., Goldberg, E., Kedem, E., Peritz, E., and Pines, A. (1993). Correlates of military tank simulator sickness. Aviat. Space Environ. Med. 64, 619-622.

Lin, C. J., Chen, H. J., Cheng, P. Y., and Sun, T. L. (2015). Effects of displays on visually controlled task performance in three-dimensional virtual reality environment. Hum. Factors Ergon. Manuf. Serv. Ind. 25, 523-533. doi: 10.1002/ hfm.20566

Lin, J. W., Duh, H. B. L., Parker, D. E., Abi-Rached, H., and Furness, T. A. (2002). "Effects of field of view on presence, enjoyment, memory, and simulator sickness in a virtual environment," in Proceedings of the IEEE Proceedings of Virtual Reality, 2002, (Piscataway, NJ: IEEE), 164-171. doi: 10.1109/VR.2002. 996519

Ling, Y., Nefs, H. T., Brinkman, W. P., Qu, C., and Heynderickx, I. (2013). The relationship between individual characteristics and experienced presence. Comput. Hum. Behav. 29, 1519-1530. doi: 10.1016/j.chb.2012.12.010

Liu, C. L., and Uang, S. T. (2011). "Effects of presence on causing cybersickness in the elderly within a 3D virtual store," in Proceedings of the International Conference on Human-Computer Interaction, July 2011, (Cham: Springer), 490-499. doi: 10.1007/978-3-642-21619-0_61

Lombard, M., and Ditton, T. (1997). At the heart of it all: the concept of presence. J. Comput. Med. Commun. 3:JCMC321, doi: 10.1111/j.1083-6101.1997. tb00072.x

Lombard, M., Reich, R. D., Grabe, M. E., Bracken, C. C., and Ditton, T. B. (2000). Presence and television. Hum. Commun. Res. 26, 75-98. doi: 10.1111/j.14682958.2000.tb00750.x

Mania, K., and Chalmers, A. (2001). The effects of levels of immersion on memory and presence in virtual environments: a reality centered approach. Cyberpsychol. Behav. 4, 247-264. doi: 10.1089/109493101300117938

McCauley, M. E., and Sharkey, T. J. (1992). Cybersickness: perception of selfmotion in virtual environments. Presence Teleoper. Virtual Environ. 1, 311-318. doi: 10.1162/pres.1992.1.3.311

Meehan, M., Insko, B., Whitton, M., and Brooks, F. P. (2001). "Physiological measures of presence in stressful virtual environments," in Proceedings of the 4th International Workshop on Presence, Philadelphia, PA, 21-23,

Meehan, M., Razzaque, S., Whitton, M. C., and Brooks, F. P. Jr. (2003). "Effect of latency on presence in stressful virtual environments," in Proceedings of the IEEE Virtual Reality, (Piscataway, NJ: IEEE), 141-148. doi: 10.1109/VR.2003.1191132

Miller, A. D., and Wilson, V. J. (1983). Vestibular-induced vomiting after vestibulocerebellar lesions. Brain Behav. Evol. 23, 26-31. doi: 10.1159/ 000121484

Milleville-Pennel, I., and Charron, C. (2015). Do mental workload and presence experienced when driving a real car predispose drivers to simulator sickness? An exploratory study. Accid. Anal. Prev. 74, 192-202. doi: 10.1016/j.aap.2014. 10.021

Minsky, M. (1980). Telepresence. Omni 2, 44-52.

Moher, D., Liberati, A., Tetzlaff, J., and Altman, D. G. (2009). Preferred reporting items for systematic reviews and meta-analyses: the PRISMA statement. Ann. Intern. Med. 151, 264-269. doi: 10.7326/0003-4819-151-4-200908180-00135

Moss, J. D., and Muth, E. R. (2011). Characteristics of head-mounted displays and their effects on simulator sickness. Hum. Factors 53, 308-319. doi: 10.1177/ 0018720811405196

Nalivaiko, E., Davis, S. L., Blackmore, K. L., Vakulin, A., and Nesbitt, K. V. (2015). Cybersickness provoked by head-mounted display affects cutaneous vascular tone, heart rate and reaction time. Physiol. Behav. 151, 583-590. doi: 10.1016/j. physbeh.2015.08.043

Nelson, W. T., Roe, M. M., Bolia, R. S., and Morley, R. M. (2000). Assessing simulator sickness in a see-through HMD: effects of time delay, time on task, and task complexity (No. ASC-00-1047). Wright-Patterson Air Force Base, OH: Air Force Research Lab. doi: 10.21236/ADA430344

Nichols, S., Haldane, C., and Wilson, J. R. (2000). Measurement of presence and its consequences in virtual environments. Int. J. Hum. Comput. Stud. 52, 471-491. doi: 10.1006/ijhc.1999.0343

Nicovich, S. G., Boller, G. W., and Corwell, T. B. (2005). Experienced presence within computer-mediated communications: initial explorations on the effects of gender with respect to empathy and immersion. J. Comput. Med. Commun. 10, 1-17. doi: 10.1111/j.1083-6101.2005.tb00243.x

Nolin, P., Stipanicic, A., Henry, M., Lachapelle, Y., Lussier-Desrochers, D., and Allain, P. (2016). ClinicaVR: classroom-CPT: a virtual reality tool for assessing attention and inhibition in children and adolescents. Comput. Hum. Behav. 59, 327-333. doi: 10.1016/j.chb.2016.02.023

Oculus, V. R. (2017). Best Practices Guide. Version 310-30000-02. Available at: https://static.oculus.com/documentation/pdfs/intro-vr/latest/bp.pdf 
Ohyama, S., Nishiike, S., Watanabe, H., Matsuoka, K., Akizuki, H., Takeda, N., et al. (2007). Autonomic responses during motion sickness induced by virtual reality. Auris Nasus Larynx 34, 303-306. doi: 10.1016/j.anl.2007.01.002

Oman, C. M. (1991). "Sensory conflict in motion sickness: an observer theory approach," in Pictorial Communication in Virtual and Real Environments, eds S. R. Ellis, M. K. Kaiser, and A. J. Grunwald (London: Taylor and Francis), 362-376.

Oman, C. M., and Cullen, K. E. (2014). Brainstem processing of vestibular sensory exafference: implications for motion sickness etiology. Exp. Brain Res. 232, 2483-2492. doi: 10.1007/s00221-014-3973-2

Open Science and Collaboration (2012). An open, large-scale, collaborative effort to estimate the reproducibility of psychological science. Perspect. Psychol. Sci. 7, 657-660. doi: 10.1177/1745691612462588

Open Science Collaboration. (2015). Estimating the reproducibility of psychological science. Science 349:aac4716. doi: 10.1126/science.aac 4716

Paillard, A. C., Quarck, G., Paolino, F., Denise, P., Paolino, M., Golding, J. F., et al. (2013). Motion sickness susceptibility in healthy subjects and vestibular patients: effects of gender, age and trait-anxiety. J. Vestib. Res. 23, 203-209.

Palmisano, S., Kim, J., and Freeman, T. C. (2012). Horizontal fixation point oscillation and simulated viewpoint oscillation both increase vection in depth. J. Vis. 12:15. doi: 10.1167/12.12.15

Palmisano, S., Mursic, R., and Kim, J. (2017). Vection and cybersickness generated by head-and-display motion in the Oculus Rift. Displays 46, 1-8. doi: 10.1016/j. displa.2016.11.001

Park, G. D., Allen, R. W., Fiorentino, D., Rosenthal, T. J., and Cook, M. L. (2006). Simulator sickness scores according to symptom susceptibility, age, and gender for an older driver assessment study. Proc. Hum. Factors Ergon. Soc. Ann. Meet. 50, 2702-2706. doi: 10.1177/154193120605002607

Peer, A., and Ponto, K. (2017). "Evaluating perceived distance measures in roomscale spaces using consumer-grade head mounted displays," in Proceedings of the IEEE Symposium on 3D User Interfaces (3DUI), March 2017, (Piscataway, NJ: IEEE), 83-86. doi: 10.1109/3DUI.2017.7893321

Pölönen, M., Salmimaa, M., Aaltonen, V., Häkkinen, J., and Takatalo, J. (2009). Subjective measures of presence and discomfort in viewers of color-separationbased stereoscopic cinema. J. Soc. Inf. Disp. 17, 459-466. doi: 10.1889/JSID17. 5.459

Prothero, J. D. (1998). The Role of Rest Frames in Vection, Presence and Motion Sickness. Ph.D. thesis, University of Washington, Seattle, WA.

Prothero, J. D., and Hoffman, H. D. (1995). Widening the Field-of-View Increases the Sense of Presence Within Immersive Virtual Environments. Human Interface Technology Laboratory Technical Report, No. 5-4. Seattle, WA: University of Washington.

Prothero, J. D., and Parker, D. E. (2003). "A unitied approach to presence and motion sickness," in Virtual and Adaptive Environments: Applications, Implications, and Human Performance Issues, eds L. J. Hettinger and L. W. Haas (Boca Raton, FL: CRC Press), 61-80.

Reason, J. T., and Brand, J. J. (1975). Motion Sickness. Cambridge, MA: Academic Press.

Rebenitsch, L., and Owen, C. (2016). Review on cybersickness in applications and visual displays. Virtual Real. 20, 101-125. doi: 10.1007/s10055-016-0285-9

Reed-Jones, R. J., Reed-Jones, J. G., Trick, L. M., and Vallis, L. A. (2007). "Can galvanic vestibular stimulation reduce simulator adaptation syndrome?", in Proceedings of the 4th International Driving Symposium on Human Factors in Driver Assessment, Training and Vehicle Design 2007, (Stevenson, WA), 534-540. doi: 10.17077/drivingassessment.1288

Riccio, G. E., and Stoffregen, T. A. (1991). An ecological theory of motion sickness and postural instability. Ecol. Psychol. 3, 195-240. doi: 10.1207/ s15326969eco0303_2

Riecke, B. E. (2010). Compelling Self-motion Through Virtual Environments Without Actual Self-Motion-Using Self-Motion Illusions ('vection') to Improve VR User Experience in Virtual Reality. London: InTech Open.

Riecke, B. E., and Jordan, J. D. (2015). Comparing the effectiveness of different displays in enhancing illusions of self-movement (vection). Front. Psychol. 6:713. doi: 10.3389/fpsyg.2015.00713

Robillard, G., Bouchard, S., Fournier, T., and Renaud, P. (2003). Anxiety and presence during VR immersion: a comparative study of the reactions of phobic and non-phobic participants in therapeutic virtual environments derived from computer games. Cyberpsychol. Behav. 6, 467-476. doi: 10.1089/ 109493103769710497

Rolnick, A., and Lubow, R. E. (1991). Why is the driver rarely motion sick? The role of controllability in motion sickness. Ergonomics 34, 867-879. doi: 10.1080/ 00140139108964831

Rothbaum, B. O., and Hodges, L. F. (1999). The use of virtual reality exposure in the treatment of anxiety disorders. Behav. Modif. 23, 507-525. doi: 10.1177/ 0145445599234001

Ryan, V., and Griffin, R. (2016). An investigation into anxiety in virtual reality following a self-compassion induction. Ann. Rev. Cyberther. Telemed. 14, 109-114.

Sacau, A., Laarni, J., and Hartmann, T. (2008). Influence of individual factors on presence. Comput. Hum. Behav. 24, 2255-2273. doi: 10.1016/j.chb.2007.11.001

Sadowski, W., and Stanney, K. (2002). "Presence in virtual environments," in Handbook of Virtual Environments: Design, Implementation, and Applications, ed. K. M. Stanney (Boca Raton: FL: CRC Press), 791-807.

Sanchez-Vives, M. V., and Slater, M. (2005). From presence to consciousness through virtual reality. Nat. Rev. Neurosci. 6, 332-339. doi: 10.1038/nrn1651

Schubert, T. (2003). The sense of presence in virtual environments: a threecomponent scale measuring spatial presence, involvement, and realness. Z. Medienpsychol. 15, 69-71. doi: 10.1026//1617-6383.15.2.69

Schuemie, M. J., Abel, B., van der Mast, C. A. P. G., Krijn, M., and Emmelkamp, P. M. G. (2005). "The effect of locomotion technique on presence, fear and usability in a virtual environment," in Proceedings of the EUROMEDIA '2005: 11th Annual Euromedia Conference, Ghent: Eurosis-ETI 129-135.

Schuemie, M. J., van der Straaten, P., Krijn, M., and van der Mast, C. A. P. G. (2001). Research on presence in virtual reality: a survey. CyberPsychol. Behav. 4, 183-201. doi: 10.1089/109493101300117884

Seay, A. F., Krum, D. M., Hodges, L., and Ribarsky, W. (2002). "Simulator sickness and presence in a high field-of-view virtual environment," in Proceedings of the CHI'02 Extended Abstracts on Human Factors in Computing Systems, April 2002, (New York, NY: ACM), 784-785. doi: 10.1145/506443.506596

Serafin, S., Erkut, C., Kojs, J., Nilsson, N. C., and Nordahl, R. (2016). Virtual reality musical instruments: State of the art, design principles, and future directions. Comput. Music J. 40, 22-40. doi: 10.1162/COMJ_a_00372

Sharples, S., Cobb, S. V., Moody, A., and Wilson, J. R. (2008). Virtual reality induced symptoms and effects (VRISE): comparison of head mounted display (HMD), desktop and projection display systems. Displays 29, 58-69. doi: 10. 1016/j.displa.2007.09.005

Sheridan, T. (1992). Musings on telepresence and virtual presence. Presence Teleoper. Virtual Environ. 1, 120-126. doi: 10.1162/pres.1992.1.1.120

Singer, M. J., Ehrlich, J., and Cinq-Mars, S. (1995). Task Performance in Virtual Environments: Stereoscopic Versus Monoscopic Displays and HeadCoupling (No. ARI-TR-1034). Alexandria, VA: Army Research Institute for the Behavioral.

Slater, M. (2004a). How colorful was your day? Why questionnaires cannot assess presence in virtual environments. Presence Teleoper. Virtual Environ. 13, 484-493.

Slater, M. (2004b). Presence and emotions. Cyberpsychol. Behav. 7, 121-121. doi: $10.1089 / 109493104322820200$

Slater, M. (2009). Place illusion and plausibility can lead to realistic behaviour in immersive virtual environments. Philos. Trans. R. Soc. Lond. B. Biol. Sci. 364, 3549-3557. doi: 10.1098/rstb.2009.0138

Slater, M., Linakis, V., Usoh, M., Kooper, R., and Street, G. (1996). "Immersion, presence, and performance in virtual environments: an experiment with tridimensional chess," in ACM virtual reality software and technology (VRST), July 1996, Vol. 163, (New York, NY: ACM Press), 72. doi: 10.1145/3304181. 3304216

Slater, M., Pérez Marcos, D., Ehrsson, H., and Sanchez-Vives, M. V. (2009). Inducing illusory ownership of a virtual body. Front. Neurosci. 3, 214-220. doi: 10.3389/neuro.01.029.2009

Slater, M., Steed, A., McCarthy, J., and Maringelli, F. (1998). The influence of body movement on subjective presence in virtual environments. Hum. Factors 40, 469-477. doi: 10.1518/001872098779591368

Slater, M., and Usoh, M. (1993). Representations systems, perceptual position, and presence in immersive virtual environments. Presence Teleoper. Virtual Environ. 2, 221-233. doi: 10.1162/pres.1993.2.3.221 
Slater, M., and Usoh, M. (1994). Body centred interaction in immersive virtual environments. Artif. Life Virtual Real. 1, 125-148.

Slater, M., Usoh, M., and Steed, A. (1995). Taking steps: the influence of a walking technique on presence in virtual reality. ACM Trans. Comput. Hum. Interact. 2, 201-219. doi: 10.1145/210079.210084

Smolentsev, A., Cornick, J. E., and Blascovich, J. (2017). Using a preamble to increase presence in digital virtual environments. Virtual Real. 21, 153-164. doi: 10.1007/s10055-017-0305-4

Stanney, K. M., and Hash, P. (1998). Locus of user-initiated control in virtual environments: Influences on cybersickness. Presence Teleoper. Virtual Environ. 7, 447-459. doi: 10.1162/105474698565848

Stanney, K. M., Kennedy, R. S., and Drexler, J. M. (1997). “Cybersickness is not simulator sickness," in Proceedings of the Human Factors and Ergonomics Society annual meeting, October 1997, Vol. 41, (Los Angeles, CA: Sage Publications), 1138-1142. doi: 10.1177/107118139704100292

Stanney, K. M., Kingdon, K. S., Graeber, D., and Kennedy, R. S. (2002). Human performance in immersive virtual environments: effects of exposure duration, user control, and scene complexity. Hum. Perform. 15, 339-366. doi: 10.1207/ S15327043HUP1504_03

Stanney, K. M., Mourant, R. R., and Kennedy, R. S. (1998). Human factors issues in virtual environments: a review of the literature. Presence 7, 327-351. doi: $10.1162 / 105474698565767$

Stern, R. M., Hu, S., Uijtdehaage, S. H., Muth, E. R., Xu, L. H., and Koch, K. L. (1996). Asian hypersusceptibility to motion sickness. Hum. Heredity 46, 7-14. doi: $10.1159 / 000154318$

Sutherland, I. E. (1968). "A head-mounted three dimensional display," in Proceedings of the Fall Joint Computer Conference, Part I, December 9-11 (New York, NY: ACM), 757-764.

Tanaka, N., and Takagi, H. (2004). Virtual reality environment design of managing both presence and virtual reality sickness. J. Physiol. Anthropol. Appl. Hum. Sci. 23, 313-317. doi: 10.2114/jpa.23.313

Terziman, L., Marchal, M., Emily, M., Multon, F., Arnaldi, B., and Lécuyer, A. (2010). "Shake-your-head: revisiting walking-in-place for desktop virtual reality," in Proceedings of the 17th ACM Symposium on Virtual Reality Software and Technology, November 2010, (Gothenburg), 27-34. doi: 10.1145/1889863. 1889867

Treisman, M. (1977). Motion sickness: an evolutionary hypothesis. Science 197, 493-495. doi: 10.1126/science.301659

Triberti, S., and Riva, G. (2016). Being present in action: a theoretical model about the "interlocking" between intentions and environmental affordances. Front. Psychol. 6:2052. doi: 10.3389/fpsyg.2015.02052

Usoh, M., Arthur, K., Whitton, M. C., Bastos, R., Steed, A., Slater, M., et al. (1999). "Walking > walking-in-place > flying, in virtual environments," in Proceedings of the 26th Annual Conference on Computer Graphics and Interactive Techniques, July 1999, (New York, NY: ACM Press), 359-364. doi: 10.1145/311535.311589

Usoh, M., Catena, E., Arman, S., and Slater, M. (2000). Using presence questionnaires in reality. Presence Teleoper. Virtual Environ. 9, 497-503. doi: $10.1162 / 105474600566989$

van Baren, J., and IJsselsteijn, W. (2004). Measuring Presence: A Guide to Current Measurement Approaches. Deliverable of the OmniPres Project IST-200139237.

Van de Mortel, T. F. (2008). Faking it: social desirability response bias in self-report research. Aust. J. Adv. Nurs. 25, 40-48.

Viaud-Delmon, I., Ivanenko, Y. P., Berthoz, A., and Jouvent, R. (1998). Sex, lies and virtual reality. Nat. Neurosci. 1:15.

Viaud-Delmon, I., Ivanenko, Y. P., Berthoz, A., and Jouvent, R. (2000). Adaptation as a sensorial profile in trait anxiety: a study with virtual reality. J. Anxiety Disord. 14, 583-601. doi: 10.1016/S0887-6185(00)00052-9

Viaud-Delmon, I., Warusfel, O., Seguelas, A., Rio, E., and Jouvent, R. (2006). High sensitivity to multisensory conflicts in agoraphobia exhibited by virtual reality. Eur. Psychiatry 21, 501-508. doi: 10.1016/j.eurpsy.2004. 10.004

Waterworth, J. A., Waterworth, E. L., Riva, G., and Mantovani, F. (2015). "Presence: Form, content and consciousness," in Immersed in Media:
Telepresence Theory, Measurement \& Technology, eds M. Lombard, F. Biocca, J. Freeman, W. IJsselsteijn, and R. J. Schaevitz (Cham: Springer), 35-58.

Webb, N. A., and Griffin, M. J. (2003). Eye movement, vection, and motion sickness with foveal and peripheral vision. Aviat. Space Environ. Med. 74, 622-625.

Weech, S., Moon, J., and Troje, N. F. (2018a). Influence of bone-conducted vibration on simulator sickness in virtual reality. PLoS One 13:e0194137. doi: 10.1371/journal.pone.0194137

Weech, S., Varghese, J. P., and Barnett-Cowan, M. (2018b). Estimating the sensorimotor components of cybersickness. J. Neurophysiol. 120, 2201-2217. doi: $10.1152 /$ jn. 00477.2018

Weech, S., and Troje, N. F. (2017). Vection latency is reduced by bone-conducted vibration and noisy galvanic vestibular stimulation. Multisens. Res. 30, 65-90. doi: 10.1163/22134808-00002545

Weibel, D., Wissmath, B., and Mast, F. W. (2010). Immersion in mediated environments: the role of personality traits. Cyberpsychol. Behav. Soc. Netw. 13, 251-256. doi: 10.1089/cyber.2009.0171

Welch, R. B., Blackmon, T. T., Liu, A., Mellers, B. A., and Stark, L. W. (1996). The effects of pictorial realism, delay of visual feedback, and observer interactivity on the subjective sense of presence. Presence Teleoper. Virtual Environ. 5, 263-273. doi: 10.1162/pres.1996.5.3.263

Wiederhold, B. K., Jang, D. P., Kaneda, M., Cabral, I., Lurie, Y., May, T., et al. (2001). "An investigation into physiological responses in virtual environments: an objective measurement of presence," in Towards CyberPsychology: Mind, Cognitions and Society in the Internet Age, eds G. Riva and C. Galimberti (Amsterdam,: Ios Press).

Wilson, J. R., Nichols, S., and Haldane, C. (1997). "Presence and side effects: complementary or contradictory?", in Proceedings of the 7th International Conference on Human-Computer Interaction, Amsterdam: Elsevier Science Publishers, 889-892.

Witmer, B. G., Bailey, J. H., Knerr, B. W., and Parsons, K. C. (1996). Virtual spaces and real world places: transfer of route knowledge. Int. J. Hum. Comput. Stud. 45, 413-428. doi: 10.1006/ijhc. 1996.0060

Witmer, B. G., and Singer, M. J. (1994). Measuring Immersion in Virtual Environments. Technical Report 1014. Alexandria, VA: U.S. Army Research Institute. doi: 10.21236/ADA286183

Witmer, B. G., and Singer, M. J. (1998). Measuring presence in virtual environments: a presence questionnaire. Presence Teleoper. Virtual Environ. 7, 225-240. doi: 10.1162/105474698565686

Wong, S. C. P., and Frost, B. J. (1981). The effect of visual-vestibular conflict on the latency of steady-state visually induced subjective rotation. Percept. Psychophys. 30, 228-236. doi: 10.3758/BF03214278

Yates, B. J., Miller, A. D., and Lucot, J. B. (1998). Physiological basis and pharmacology of motion sickness: an update. Brain Res. Bull. 47, 395-406. doi: 10.1016/S0361-9230(98)00092-6

Zao, J. K., Jung, T. P., Chang, H. M., Gan, T. T., Wang, Y. T., Lin, Y. P., et al. (2016). "Augmenting VR/AR applications with EEG/EOG monitoring and oculo-vestibular recoupling," in Proceedings of the International Conference on Augmented Cognition, July 2016, (Cham: Springer), 121-131. doi: 10.1007/9783-319-39955-3_12

Zimmons, P., and Panter, A. (2003). "The influence of rendering quality on presence and task performance in a virtual environment," in Proceedings of the IEEE Virtual Reality, March 2003, (Los Angeles, CA: IEEE Computer Society). 293-294. doi: 10.1109/VR.2003.1191170

Conflict of Interest Statement: The authors declare that the research was conducted in the absence of any commercial or financial relationships that could be construed as a potential conflict of interest.

Copyright (c) 2019 Weech, Kenny and Barnett-Cowan. This is an open-access article distributed under the terms of the Creative Commons Attribution License (CC BY). The use, distribution or reproduction in other forums is permitted, provided the original author(s) and the copyright owner(s) are credited and that the original publication in this journal is cited, in accordance with accepted academic practice. No use, distribution or reproduction is permitted which does not comply with these terms. 